\title{
On the isolation of $\mathrm{OC}$ and $\mathrm{EC}$ and the optimal strategy of radiocarbon-based source apportionment of carbonaceous aerosols
}

\author{
Y. L. Zhang ${ }^{1,2,3}$, N. Perron ${ }^{2, *}$, V. G. Ciobanu ${ }^{2}$, P. Zotter ${ }^{2}$, M. C. Minguillón ${ }^{2,4}$, L. Wacker $^{5}$, A. S. H. Prévôt ${ }^{2}$, \\ U. Baltensperger ${ }^{2}$, and S. Szidat ${ }^{1,3}$ \\ ${ }^{1}$ Department of Chemistry and Biochemistry, University of Bern, Freiestrasse 3, 3012 Bern, Switzerland \\ ${ }^{2}$ Paul Scherrer Institute (PSI), Villigen, Switzerland, 5232 Villigen, Switzerland \\ ${ }^{3}$ Oeschger Centre for Climate Change Research, University of Bern, 3012 Bern, Switzerland \\ ${ }^{4}$ Institute of Environmental Assessment and Water Research (IDAEA), CSIC, 08034 Barcelona, Spain \\ ${ }^{5}$ Laboratory of Ion Beam Physics, ETH Hönggerberg, 8093 Zürich, Switzerland \\ *now at: Devision of Nuclear Physics, Lund University, 22100 Lund, Sweden
}

Correspondence to: S. Szidat (szidat@ iac.unibe.ch)

Received: 27 June 2012 - Published in Atmos. Chem. Phys. Discuss.: 18 July 2012

Revised: 12 October 2012 - Accepted: 12 November 2012 - Published: 16 November 2012

\begin{abstract}
Radiocarbon $\left({ }^{14} \mathrm{C}\right)$ measurements of elemental carbon (EC) and organic carbon (OC) separately (as opposed to only total carbon, TC) allow an unambiguous quantification of their non-fossil and fossil sources and represent an improvement in carbonaceous aerosol source apportionment. Isolation of $\mathrm{OC}$ and $\mathrm{EC}$ for accurate ${ }^{14} \mathrm{C}$ determination requires complete removal of interfering fractions with maximum recovery. The optimal strategy for ${ }^{14} \mathrm{C}$-based source apportionment of carbonaceous aerosols should follow an approach to subdivide TC into different carbonaceous aerosol fractions for individual ${ }^{14} \mathrm{C}$ analyses, as these fractions may differ in their origins. To evaluate the extent of positive and negative artefacts during OC and EC separation, we performed sample preparation with a commercial ThermoOptical OC/EC Analyser (TOA) by monitoring the optical properties of the sample during the thermal treatments. Extensive attention has been devoted to the set-up of TOA conditions, in particular, heating program and choice of carrier gas. Based on different types of carbonaceous aerosols samples, an optimised TOA protocol (Swiss_4S) with four steps is developed to minimise the charring of $\mathrm{OC}$, the premature combustion of $\mathrm{EC}$ and thus artefacts of ${ }^{14} \mathrm{C}$-based source apportionment of EC. For the isolation of $\mathrm{EC}$ for ${ }^{14} \mathrm{C}$ analysis, the water-extraction treatment on the filter prior to any thermal treatment is an essential prerequisite for subsequent radiocarbon measurements; otherwise the non-fossil contribution may be overestimated due to the positive bias from
\end{abstract}

charring. The Swiss 4 S protocol involves the following consecutive four steps (S1, S2, S3 and S4): (1) S1 in pure oxygen $\left(\mathrm{O}_{2}\right)$ at $375^{\circ} \mathrm{C}$ for separation of $\mathrm{OC}$ for untreated filters and water-insoluble organic carbon (WINSOC) for waterextracted filters; (2) $\mathrm{S} 2$ in $\mathrm{O}_{2}$ at $475^{\circ} \mathrm{C}$ followed by (3) $\mathrm{S} 3$ in helium $(\mathrm{He})$ at $650{ }^{\circ} \mathrm{C}$, aiming at complete $\mathrm{OC}$ removal before EC isolation and leading to better consistency with thermal-optical protocols like EUSAAR_2, compared to pure oxygen methods; and (4) $\mathrm{S} 4$ in $\mathrm{O}_{2}$ at $760^{\circ} \mathrm{C}$ for recovery of the remaining EC.

WINSOC was found to have a significantly higher fossil contribution than the water-soluble OC (WSOC). Moreover, the experimental results demonstrate the lower refractivity of wood-burning EC compared to fossil EC and the difficulty of clearly isolating $\mathrm{EC}$ without premature evolution. Hence, simplified techniques of EC isolation for ${ }^{14} \mathrm{C}$ analysis are prone to a substantial bias and generally tend towards an overestimation of fossil sources. To obtain the comprehensive picture of the sources of carbonaceous aerosols, the Swiss_4S protocol is not only implemented to measure OC and EC fractions, but also WINSOC as well as a continuum of refractory OC and non-refractory EC for ${ }^{14} \mathrm{C}$ source apportionment. In addition, WSOC can be determined by subtraction of the water-soluble fraction of TC from untreated TC. Last, we recommend that ${ }^{14} \mathrm{C}$ results of EC should in general be reported together with the EC recovery. 


\section{Introduction}

Carbonaceous aerosols are of worldwide concern due to their effects on climate and air quality (Highwood and Kinnersley, 2006; Mauderly and Chow, 2008). The total carbon (TC) content of this highly variable mixture, made of extremely different and mainly unidentified compounds (Turpin et al., 2000) is usually divided into two sub-fractions: weakly refractory and light polycyclic or polyacidic hydrocarbons (organic carbon, OC) and strongly refractory and highly polymerized carbon (elemental carbon, EC), which is also designated as black carbon (BC) (Castro et al., 1999; Pöschl, 2005). Particulate EC derives from incomplete combustion of fossil fuels and biomass, whereas OC originates from either primary emissions or secondary organic carbon (SOC) formation (Pöschl, 2005). Since OC and EC play decisive but different roles in the global climate and on human health, assessing their respective source strengths is needed for a better understanding of their influences as well as for efficient abatement strategies. Such a source apportionment can be performed by measuring the radiocarbon $\left({ }^{14} \mathrm{C}\right)$ content of $\mathrm{OC}$ and EC separately, which provides direct and additional information about their contemporary and fossil sources (Currie, 2000; Szidat, 2009; Szidat et al., 2009).

Since both fractions differ in their origins and processes, they often show very different ${ }^{14} \mathrm{C}$ signatures (Szidat et al., 2004b, 2006, 2007; Szidat, 2009). Therefore, the ${ }^{14} \mathrm{C}$-based source apportionment method requires a clear and physical separation between OC and EC; however, this is not trivial. Indeed, the distinction between OC and EC is based on a conceptual and operational definition and does not correspond in reality to a clear boundary. On the one hand, OC compounds become more chemically refractory and optically absorbing with increasing molecular weight. On the other hand, EC also presents a continuum (Elmquist et al., 2006), the least refractory part of which may show a chemical and physical behaviour similar to high-molecular-weight OC compounds. Consequently, thermal separation of OC and EC may suffer from untimely EC removal (Andreae and Gelencsér, 2006), described as the negative EC artefact. These losses are particularly enhanced for wood-burning-impacted samples because of the presence of inorganic combustion catalysts (Novakov and Corrigan, 1995) and of the lower refractivity of the wood-burning EC compared to fossil EC (Elmquist et al., 2006).

The classification of OC and EC is widely acknowledged, but their boundary is still not clear and highly operationaldependent (Schmid et al., 2001; Pöschl, 2005). Among the commonly accepted OC/EC determination methods, the thermal-optical analysis (TOA) method is one of the most well-known techniques (Schmid et al., 2001; Chow et al., 2004; Phuah et al., 2009; Cavalli et al., 2010). It typically begins with a heating step in an inert (i.e. helium) atmosphere, aiming at evaporating OC exclusively. An oxidative gas (e.g. $2 \%$ oxygen in helium) is then introduced in a second step to oxidise the remaining material, assumed to contain the entire EC fraction. Differentiation between OC and EC relies on the prerequisite that these components can be distinguished by their volatilization and oxidation properties. However, OC can partially be converted into EC through a pyrolysis $(\mathrm{Ca}-$ dle et al., 1980) during the inert step, which induces a positive artefact in the determination of EC in the second step. Because of this process, known as charring, OC may be underestimated and EC may be overestimated. The correction of charring in TOA method is applied by continuously monitoring the transmittance or reflectance of the sample filter during analysis (Birch and Cary, 1996; Chow et al., 2001). The OC-EC split is generally defined as the point where the transmittance or reflectance level returns to its initial level after a transient reduction of the laser response due to $\mathrm{OC}$ charring. The remaining carbon after the split point during the oxidative mode is regarded as EC.

Huang et al. (2006) developed a method to measure ${ }^{13} \mathrm{C} /{ }^{12} \mathrm{C}$ ratios of individual carbon fractions of airborne particular matter from filter samples using a TOA OC/EC analyser coupled with an isotopic ratio mass spectrometer (GCIRMS). However, such TOA methods have not yet been applied to isolate EC and $\mathrm{OC}$ for ${ }^{14} \mathrm{C}$ analysis. The largest challenge is to define a split point between $\mathrm{OC}$ and $\mathrm{EC}$ for individual isolation of both fractions. The split point between OC and EC in conventional TOA protocols (such as EUSAAR_2, NIOSH and IMPROVE) cannot be directly used for separation of the desired carbon fractions for ${ }^{14} \mathrm{C}$ measurement, because it does not provide a chemical boundary between OC and EC. Indeed, the split between charred OC and EC relies notably on the assumptions that both materials present the same mass absorption efficiency or that charred OC evolves completely before EC oxidation starts, both of which have been reported not to be the case for most samples (Yang and $\mathrm{Yu}, 2002$; Bond and Bergstrom, 2006). Therefore, the carbonaceous material evolved after the split point with conventional TOA protocols, albeit quantified as EC, may contain a mix of EC and charred $\mathrm{OC}$ and is therefore inappropriate for ${ }^{14} \mathrm{C}$ analysis of EC. Consequently, a main difficulty consists in achieving complete OC removal before EC isolation.

In an effort to reduce both above-mentioned artefacts, especially charring, Cachier et al. (1989) replaced the evaporation step by the combustion of OC in pure oxygen $\left(\mathrm{O}_{2}\right)$. This two-step combustion method was further optimised for OC and EC quantification by Lavanchy et al. (1999) and then adapted to a Two-step Heating system for the EC/OC Determination Of Radiocarbon in the Environment (THEODORE, Szidat et al., 2004a), which was then adopted by many other laboratories (e.g. Zhang et al., 2010; Calzolai et al., 2011). A technique with chemo-thermal oxidation at $375^{\circ} \mathrm{C}$ in air (CTO-375) is also commonly applied to determine EC or BC (Gustafsson et al., 2001) and isolate EC from aerosols for subsequent off-line radiocarbon analysis (Zencak et al., 2007). Compared to methods based on OC removal in an inert atmosphere, both the two-step combustion 
method and the CTO-375 method are less prone to charring and inadvertent inclusion of any other non-pyrogenic carbon. It should be noted that the pre-treatment step of the water extraction is introduced in the THEODORE method to reduce charring further. However, both methods may also remove substantial amounts of non-refractory EC (non-rEC) during the thermal treatment, so that the isolated EC much likely reflects only the most refractory EC ( $\mathrm{rEC})$ and cannot fully represent the total EC (tEC) spectrum.

Therefore, these thermal methods do not enable the full quantification of the positive and negative $\mathrm{EC}$ artefacts due to charring and premature EC removal. As wood-burning EC was reported to be the least refractory EC fraction (Elmquist et al., 2006), parts of it may have been oxidized during the OC step, leading to an underestimation of this EC fraction. This could be especially crucial in areas where a lot of EC is due to biomass burning, as in the Alpine valleys, where residential heating is important (Szidat et al., 2007; Lanz et al., 2010).

In this study, we present an optimised procedure for the isolation of $\mathrm{OC}$ and $\mathrm{EC}$ for ${ }^{14} \mathrm{C}$ analysis, based on thermooptical OC/EC analysis. We qualitatively define EC and OC as the sub-fractions of TC that do and do not absorb light at the wavelength of thermal-optical OC/EC analysers (e.g. $660 \mathrm{~nm}$ ), respectively, following the general assumptions of conventional TOA protocols which are a prerequisite for their optical correction (Birch and Cary, 1996; Chow et al., 2001; Cavalli et al., 2010). In particular, we show how different conditions of temperatures and carrier gases influence the separation of $\mathrm{OC}$ and $\mathrm{EC}$ and the ${ }^{14} \mathrm{C}$ content of the removed carbon fractions. Furthermore, an optimised TOA protocol is developed to isolate the carbon fractions of interest (i.e. OC and EC) for ${ }^{14} \mathrm{C}$ analysis with minimised biases from charring and premature EC lost. Finally, we discuss the optimum strategy of ${ }^{14} \mathrm{C}$-based source apportionment of carbonaceous aerosols, especially for EC samples.

\section{Methods}

\subsection{The previous two-step combustion method}

The THEODORE (Two-step Heating system for the EC/OC Determination Of Radiocarbon in the Environment) system (Szidat et al., 2004a) is a set-up that was previously used for the combustion and the recovery of carbonaceous fractions for ${ }^{14} \mathrm{C}$-based source apportionment. It consists of a quartz combustion tube where a filter punch is inserted and combusted under a stream of pure $\mathrm{O}_{2}$. After removal of water, the resulting $\mathrm{CO}_{2}$ is trapped cryogenically, determined manometrically and sealed in glass ampoules for subsequent ${ }^{14} \mathrm{C}$ off-line analysis.

The procedure to collect TC/OC/EC for ${ }^{14} \mathrm{C}$ analysis was described elsewhere (Szidat et al., 2004b, 2006, 2009). In brief, TC samples are prepared by combusting a punch of the

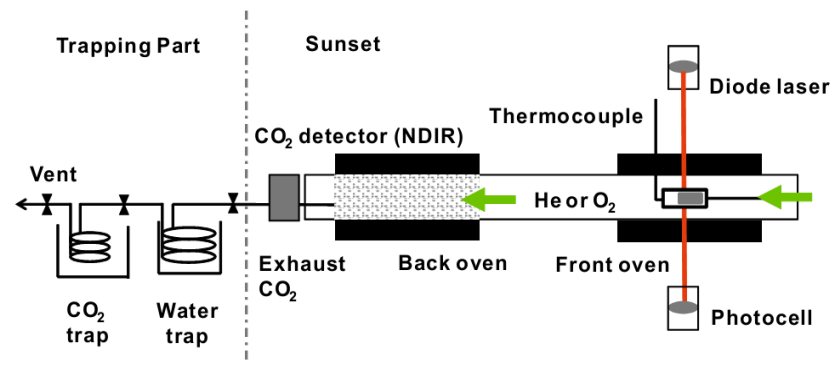

Fig. 1. Set-up of coupling the OC/EC analyser (Sunset) to the cryogenic traps.

original filter at $650^{\circ} \mathrm{C}$ during $12 \mathrm{~min}$ in the THEODORE system and recovering the $\mathrm{CO}_{2}$ as described above. For OC samples, the combustion temperature is set to $340^{\circ} \mathrm{C}$ for $10 \mathrm{~min}$. For EC isolation, water-extracted filters are heated for four hours in air at a certain temperature (e.g. $375^{\circ} \mathrm{C}$ ) to remove the remaining OC. The remaining material on the filters is regarded as EC and combusted totally in the THEODORE system at $650^{\circ} \mathrm{C}$.

\subsection{Setup of thermo-optical methods with the OC/EC analyser}

In this work, the combustion unit of the THEODORE system has been replaced by a thermo-optical OC/EC analyser (Model4L, Sunset Laboratory Inc, USA), which is especially equipped with a non-dispersive infrared (NDIR) detector. The filter transmittance is monitored by a $660-\mathrm{nm}$ tuned-diode laser and the $\mathrm{CO}_{2}$ resulting from the sample analysis quantified by an NDIR cell placed upstream the instrument outlet. This outlet is connected with a four-way valve to the $\mathrm{CO}_{2}$ cryogenic traps of the THEODORE system so as to recover the exhaust $\mathrm{CO}_{2}$ selectively corresponding to the desired fractions (Fig. 1). Additionally, a voltage control valve and a gas flow sensor are installed for $\mathrm{O}_{2}$ flow controlling. Three different ultrahigh-purity carrier gases including helium $(\mathrm{He})$ ( $>99.999 \%$, followed by a moisture/hydrocarbon $/ \mathrm{O}_{2}$ purification trap), $\mathrm{He} / \mathrm{O}_{2}$ gas ( $2 \%$ $\mathrm{O}_{2}$ in $\mathrm{He}$ ) and $\mathrm{O}_{2}$ gas $(99.9995 \%)$ as well as an internal standard gas ( $5 \%$ methane in $\mathrm{He}$ ) are controlled by the gas flow program of the instrument. The gas flow rate through the OC/EC analyser is adjusted and stabilised at $60 \mathrm{~mL} \mathrm{~min}^{-1}$. No back pressure is observed at this flow when switching valves.

\subsection{Water extraction}

For EC separation, water-extraction treatment of the filter is performed before the thermal treatment, in order to minimise charring (see Sect. 3.1). Therefore, a method was developed to obtain minimal EC removal in water with high homogeneity on the filter, which is necessary due to the narrowness ( $\sim 1 \mathrm{~mm}$ diameter) of the laser beam (J. Dixon, personal 
communication, 2010). Under a laminar flow box, 23-mmdiameter discs are punched out of the filters, sandwiched between two sealing rings and placed with the laden side upwards on a 25 -mm-diameter plastic filter holder (Sartorius $\mathrm{GmbH}$, Germany) and topped by a plastic syringe body. $20 \mathrm{~mL}$ ultrapure water with low TOC impurity is then passed through the filter without a pump. The filter punch is then delicately removed and placed for several hours in the desiccator for drying. Finally, a $1.5 \mathrm{~cm}^{2}$ rectangle is punched out of the water-extracted filter, wrapped in aluminium foil, packed into a sealed plastic bag and stored in the freezer $\left(-18^{\circ} \mathrm{C}\right)$ until OC/EC analysis.

The initial attenuation of the water-extracted filters varied up to $3 \%$ compared to that of the untreated filters, indicating that there is very little loss of EC during the water extraction procedure. Pre-acidification is omitted, because carbonate carbon (CC) is negligible in the samples of this study. However, samples may be fumigated with hydrochloric acid prior to analysis (Cachier et al., 1989) for the removal of their CC content for coarse-particle samples, particularly if they are impacted by soil dust. However, this procedure is not recommended when using a TOA analyser, since the presence of chlorides progressively makes the laser's quartz optical window opaque. In order to study the charring behaviour of water-soluble OC (WSOC), the solution obtained from water extraction is evaporated to dryness with a gentle $\mathrm{N}_{2}$ flow and then reconstituted with $200 \mu \mathrm{L}$ of water. Various amounts (e.g. $20 \mu \mathrm{L}$ ) of the water extracts are then spiked to prebaked quartz filters, and then the air-dried filters are analysed by the TOA methods.

\subsection{TOA protocol for OC/EC separation}

By using the OC/EC analyser, we aim at developing a fourstep (S1, S2, S3 and S4) thermal-optical protocol (Swiss_4S) to separate different carbon fractions from water-extracted and untreated samples for ${ }^{14} \mathrm{C}$ measurement. The parameters of this protocol will be discussed and presented in Sect. 3.2. Figure 2 sketches the separation scheme for different carbonaceous particle fractions. Specifically, OC is separated from EC during S1 applied to untreated aerosols filters, with a recovery of $\sim 80 \%$ for subsequent ${ }^{14} \mathrm{C}$ analysis. When analysing water-extracted aerosols filters, waterinsoluble OC (WINSOC), a mixture of refractory WINSOC and non-rEC as well as rEC are separated individually during $\mathrm{S} 1, \mathrm{~S} 2+\mathrm{S} 3$ and S4, respectively. Water-soluble OC (WSOC) is deduced from subtraction of TC and water-insoluble TC (WINSTC) based on mass and isotope-mass balancing.

\subsection{Quantification of EC yields and charred OC}

Similar to Gundel et al. (1984), the attenuation at the time $t$ $\left(\mathrm{ATN}_{t}\right.$, a unitless parameter) due to the light-absorbing particles on the filter is calculated from the laser transmission raw

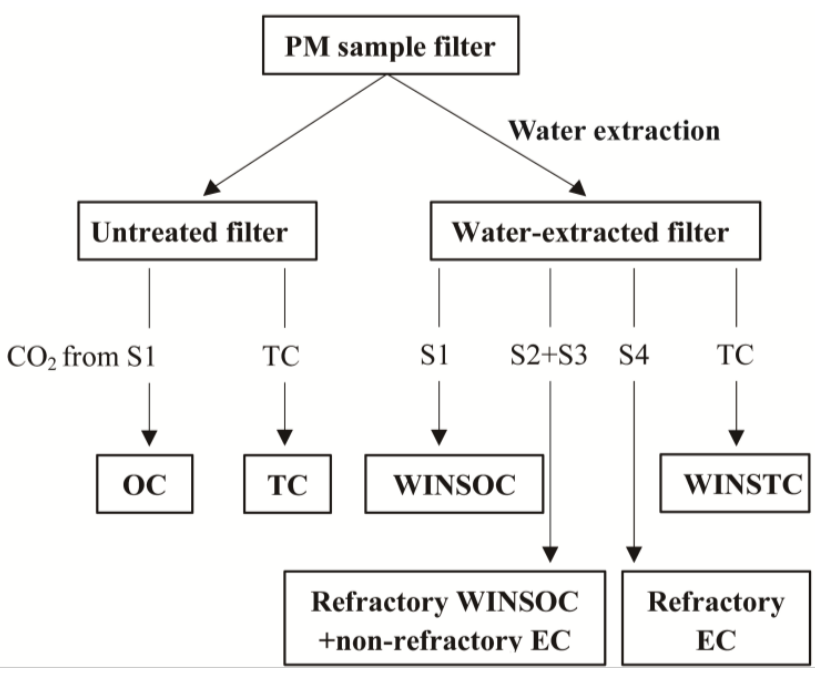

Fig. 2. Separation scheme of the different carbon fractions for ${ }^{14} \mathrm{C}$ measurement. $\mathrm{CO}_{2}$ is recovered during the desired peak in the individual step (e.g. S1, S2, S3 and/or S4) with the present protocol (Swiss_4S). Step TC means that $\mathrm{CO}_{2}$ is recovered from all steps without separation.

signal ( $I)$, using the Beer-Lambert law:

$\operatorname{ATN}_{t}=-100 \ln \frac{I_{t}}{I_{t}(b)}$

where $I_{t}$ and $I_{t}(b)$ represent the laser signal during analysis at the time $t$ and the blank signal for the same filter, respectively. The temperature dependence of $I_{t}(b)$ is assessed at the end of each run when the filter cools down after total combustion of its carbonaceous content and applied to the whole thermal programme. Thus, $I_{t}(b)$ accounts for the temperature-induced change in filter transmission and for the potential presence of light-absorbing compounds such as $\mathrm{Fe}_{2} \mathrm{O}_{3}$ remaining on the filter after combustion.

Assuming a linear relationship between ATN and the filter EC load, the optical yield of EC during analysis is defined by the ratio $\mathrm{ATN}_{t} / \mathrm{ATN}_{0}$, where $\mathrm{ATN}_{0}$ is the initial ATN, which is related to the total amount of EC on the filter, and $\operatorname{ATN}_{t}$ is the attenuation at the time $t$, when $\mathrm{S} 4$ (the EC step) begins:

EC yield $=\frac{\operatorname{ATN}_{t}}{\operatorname{ATN}_{0}}$

For the THEODORE method, offline optical measurement by the white-light aethalometer was used to determine the EC yield (Eq. 2).

Since a portion of OC is charred to an absorbing EC-like material instead being directly oxidized to $\mathrm{CO}_{2}$, the instrument relies on the change in transmission of a laser through the filter to account for charred OC. Formation of charred OC related to $\mathrm{EC}\left(f \mathrm{ATN}_{\text {char }}\right)$ is indicated as

$f \mathrm{ATN}_{\mathrm{char}}=\frac{\mathrm{ATN}_{\mathrm{max}}-\mathrm{ATN}_{i}}{\mathrm{ATN}_{i}}$ 
Table 1. Information on the filters analysed in this study.

\begin{tabular}{lllll}
\hline Location & Site type & Filter code & Sampling period & Size-cut \\
\hline \multirow{2}{*}{ Göteborg* } & \multirow{2}{*}{ Urban } & GOT1 & 11-14 February 2005 & $\mathrm{PM}_{10}$ \\
& & GOT2 & $\begin{array}{l}\text { 25 February-4 March 2005 } \\
\text { 13-20 June 2006 }\end{array}$ & $\begin{array}{l}\mathrm{PM}_{10} \\
\mathrm{PM}_{2.5}\end{array}$ \\
\hline Råö & Rural & RAO & 18-25 February 2005 & $\mathrm{PM}_{2.5}$ \\
\hline \multirow{2}{*}{ Zurich } & \multirow{2}{*}{ Urban } & ZUR1 & 19 December 2007 & $\mathrm{PM}_{10}$ \\
\hline Chiasso & Urban & CHI & 20 December 2007 & $\mathrm{PM}_{10}$ \\
\hline Solothurn & Urban & SOL & 5 January 2008 & $\mathrm{PM}_{10}$ \\
\hline Moleno & Rural & MOL & 10 January 2009 & $\mathrm{PM}_{10}$ \\
\hline Bern & Urban & BER & 14 January 2009 & $\mathrm{PM}_{10}$ \\
\hline Magadino & Rural & MAG & 14 January 2009 & $\mathrm{PM}_{10}$ \\
\hline Sissach & Suburban & SIS & 5 February 2009 & $\mathrm{PM}_{10}$ \\
\hline$*$ Sidar & & & $\mathrm{PM}_{10}$ \\
\hline
\end{tabular}

* Szidat et al. (2009)

where $\mathrm{ATN}_{\max }$ and $\mathrm{ATN}_{i}$ represent the maximum attenuation and the initial attenuation within a given thermal step, respectively.

\section{6 ${ }^{14} \mathrm{C}$ analysis}

For the recovered fractions, evolving $\mathrm{CO}_{2}$ is trapped cryogenically, quantified manometrically in a calibrated volume of the THEODORE system, and sealed in ampoules for ${ }^{14} \mathrm{C}$ measurement (Szidat et al., 2004a). Good agreement is found between the Sunset carbon amounts and the THEODORE pressure measurements (data are not shown here). ${ }^{14} \mathrm{C}$ analysis of $\mathrm{CO}_{2}$ is performed off-line with the accelerator mass spectrometer MICADAS (Synal et al., 2007) using a gas ion source (Ruff et al., 2007; Wacker et al., 2012), which allows direct $\mathrm{CO}_{2}$ injection after dilution with $\mathrm{He}$ (Ruff et al., 2010). In this study, all ${ }^{14} \mathrm{C}$ measurements are expressed as fractions of modern $\left(f_{\mathrm{M}}\right)$. This term is defined by the fraction of the measured ${ }^{14} \mathrm{C} /{ }^{12} \mathrm{C}$ ratio related to the ${ }^{14} \mathrm{C} /{ }^{12} \mathrm{C}$ ratio of the reference year 1950, which in turn is defined as 0.95-times the value of the contemporary standard for ${ }^{14} \mathrm{C}$ dating, SRM 4990B (Stuiver and Polach, 1977). All reported results are corrected for $\delta^{13} \mathrm{C}$ fractionation and for ${ }^{14} \mathrm{C}$ decay for the time period between 1950 and the year of measurement.

It is important to keep in mind that the present reported $f_{\mathrm{M}}$ is higher than the fraction of non-fossil $\left(f_{\mathrm{NF}}\right)$, because $f_{\mathrm{M}}$ of atmospheric $\mathrm{CO}_{2}$ increased greatly due to atomic bomb tests in the 1950s and 1960s (Szidat et al., 2006; Levin et al., 2010). The reported $f_{\mathrm{M}}$ can be converted to the fraction of non-fossil $\left(f_{\mathrm{NF}}\right)$ by the following equation:

$f_{\mathrm{NF}}=\frac{f_{\mathrm{M}}}{f_{\mathrm{NF}}(\mathrm{ref})}$ where $f_{\mathrm{NF}}(\mathrm{ref})$ is a reference value representing $f_{\mathrm{M}}$ of nonfossil sources during the sampling periods, which can be further separated into biogenic (bio) and biomass-burning (bb) sources given that other non-fossil sources (e.g. cooking and biofuel combustion) are negligible. Hence, $f_{\mathrm{NF}}(\mathrm{ref})$ is defined as:

$f_{\mathrm{NF}}($ ref $)=p_{\text {bio }} \times f_{\text {bio }}($ ref $)+\left(1-p_{\text {bio }}\right) \times f_{\text {bb }}($ ref $)$

where $p_{\text {bio }}$ refers to the percent of the biogenic sources to the total non-fossil sources; $f_{\mathrm{bb}}$ (ref) can be retrieved from a treegrowth model according to Mohn et al. (2008), and $f_{\text {bio }}($ ref) from the long-term time series of ${ }^{14} \mathrm{CO}_{2}$ measurements in atmosphere at the Schauinsland station (Levin et al., 2010). In the case of source apportionment of OC, $p_{\text {bio }}$ can be simply estimated as a constant value (e.g. $50 \%$ ) given that the variations of $f_{\mathrm{NF}}(\mathrm{ref})$ produced by different $p_{\text {bio }}$ values are relatively small, especially if compared to the measurement and method uncertainties (Minguillón et al., 2011). And in the case of EC, $p_{\text {bio }}$ is zero as biomass burning is the only source of non-fossil EC.

\subsection{Filter samples}

The atmospheric samples used in this study were collected by high-volume samplers on prebaked quartz-fibre filters during various field campaigns, which are compiled in Table 1. After sampling, all filters were wrapped in aluminium foils, packed in air-tight polyethylene bags and stored at $-18^{\circ} \mathrm{C}$ for later off-line analyses. 
Table 2. Parameters (carrier gas, temperature set point and duration) of the Swiss_4S protocol compared to the EUSAAR_2, modified NIOSH and IMPROVE protocols.

\begin{tabular}{|c|c|c|c|c|}
\hline & $\begin{array}{l}\text { This study } \\
\text { Swiss_4S }\end{array}$ & EUSAAR_2 & Modified NIOSH & IMPROVE \\
\hline Step & Gas, $T\left({ }^{\circ} \mathrm{C}\right), t(\mathrm{~s})$ & Gas, $T\left({ }^{\circ} \mathrm{C}\right), t(\mathrm{~s})$ & Gas, $T\left({ }^{\circ} \mathrm{C}\right), t(\mathrm{~s})$ & Gas, $T\left({ }^{\circ} \mathrm{C}\right), t(\mathrm{~s})$ \\
\hline S1 & $\begin{array}{l}\mathrm{O}_{2}, 180,50 \\
\mathrm{O}_{2}, 375,150\end{array}$ & $\begin{array}{l}\mathrm{He}, 200,120 \\
\mathrm{He}, 300,150\end{array}$ & $\begin{array}{l}\text { He, } 310,60 \\
\text { He, } 475,60\end{array}$ & $\begin{array}{l}\mathrm{He}, 120,150-580^{\mathrm{d}} \\
\mathrm{He}, 250,150-580\end{array}$ \\
\hline $\mathrm{S} 2$ & $\mathrm{O}_{2}, 475^{\mathrm{a}}, 120$ & - & - & - \\
\hline S3 & $\begin{array}{l}\mathrm{He}, 450,180 \\
\mathrm{He}, 650^{\mathrm{b}}, 180\end{array}$ & $\begin{array}{l}\mathrm{He}, 450,180 \\
\mathrm{He}, 650,180\end{array}$ & $\begin{array}{l}\mathrm{He}, 615,60 \\
\mathrm{He}, 840,90\end{array}$ & $\begin{array}{l}\mathrm{He}, 450,150-580 \\
\mathrm{He}, 550,150-580\end{array}$ \\
\hline S4 & $\begin{array}{l}\mathrm{O}_{2}, 500,120 \\
\mathrm{O}_{2}, 760,150\end{array}$ & $\begin{array}{l}\mathrm{He} / \mathrm{O}_{2}{ }^{\mathrm{c}}, 500,120 \\
\mathrm{He} / \mathrm{O}_{2}, 550,120 \\
\mathrm{He} / \mathrm{O}_{2}, 700,70 \\
\mathrm{He} / \mathrm{O}_{2}, 850,80\end{array}$ & $\begin{array}{l}\mathrm{He} / \mathrm{O}_{2}{ }^{\mathrm{c}}, 550,35 \\
\mathrm{He} / \mathrm{O}_{2}, 850,105\end{array}$ & $\begin{array}{l}\mathrm{O}_{2}, 550,150-580 \\
\mathrm{O}_{2}, 700,150-580 \\
\mathrm{O}_{2}, 800,150-580\end{array}$ \\
\hline
\end{tabular}

\footnotetext{
a The temperatures in $\mathrm{S} 2$ in the Swiss_4S protocol are tested from $425-650^{\circ} \mathrm{C}$ for optimisation.

b The temperatures in $\mathrm{S} 3$ in the Swiss_4S protocol are tested from $550-850^{\circ} \mathrm{C}$ for optimisation.

c $2 \%$ oxygen in helium.

d The residence time at each temperature in the IMPROVE protocol depends on when the detector signal returns to the baseline to achieve well-defined carbon fractions.
}

\section{Implementation of the thermo-optical OC/EC separation}

\subsection{Relevance of the charring-removing treatment}

Charred OC may not be removed totally before the split point in conventional TOA methods (e.g. IMPROVE and NIOSH) (Yu et al., 2002). As a consequence, the formation of EClike material due to $\mathrm{OC}$ charring can lead to a large bias on the $f_{\mathrm{M}}$ value of the EC fraction $\left(f_{\mathrm{M}}(\mathrm{EC})\right)$, since the modern fractions of EC and OC can differ significantly (Szidat et al., 2004b, 2009). Therefore, charring should be reduced to a minimum for an optimised $\mathrm{EC}$ isolation for ${ }^{14} \mathrm{C}$ analysis. The suppression of charring is especially achieved by water-extraction treatment on the one hand and oxidative treatment (i.e. combustion in pure $\mathrm{O}_{2}$ ) of the filters on the other hand. The water-extraction treatment prior to the EC collection substantially reduces charring due to the removal of WSOC as well as of some inorganic catalytic compounds (Novakov and Corrigan, 1995; Mayol-Bracero et al., 2002; Yu et al., 2002; Andreae and Gelencsér, 2006; Piazzalunga et al., 2011). Furthermore, Cachier et al. (1989) and Lavanchy et al. (1999) observed that charring is substantially smaller if pure oxygen is used for the OC step instead of helium.

With on-line monitoring of the optical properties of the filter during analysis, the relevance of using pure oxygen and water-extracted filters to avoid charring was assessed (Fig. 3). Five different sample filters were analysed with the OC/EC analyser using three different methods (Table 2): (1) a modified NIOSH protocol applied to untreated filters; (2) the Swiss_4S protocol applied to untreated filters; (3) the Swiss_4S protocol applied to water-extracted filters. The fil-

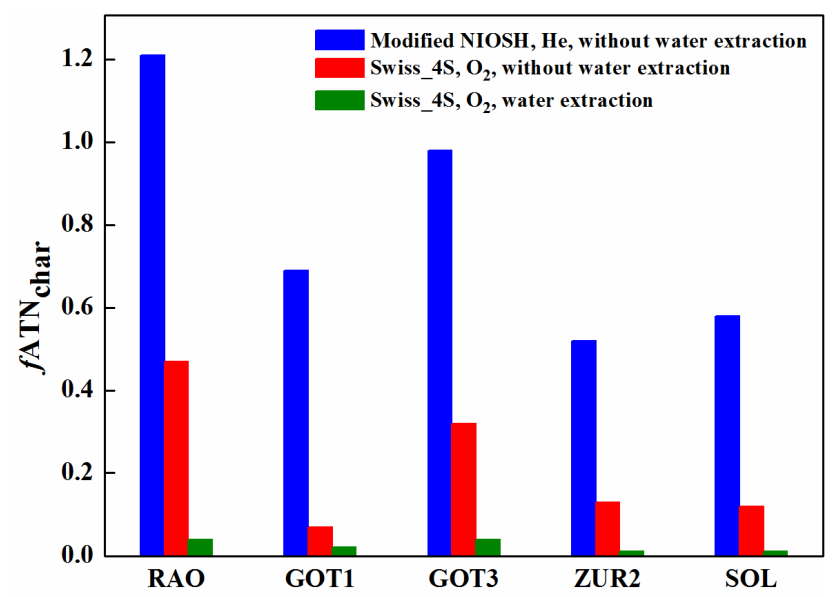

Fig. 3. Fraction of charred OC related to total $\mathrm{EC}\left(f \mathrm{ATN}_{\mathrm{char}}\right)$ during analysis using different methods for five typical samples.

ter attenuation increases by 52-121\% during the He steps of the NIOSH method, which indicates substantial formation of charred OC. Charring is substantially reduced if analysing the same filters with the Swiss_4S that uses an oxidative atmosphere (pure $\mathrm{O}_{2}$ ) before the EC step instead of an inert atmosphere (i.e. NIOSH) to remove OC. Charring is further reduced if analysis is carried out on water-extracted filters. For all studied samples including winter/summer and rural/urban samples, a charring-induced change of the ATN is reduced to $<7 \%$ of total EC if OC removal is performed under pure $\mathrm{O}_{2}$ on water-extracted filters. Furthermore, OC isolation in $\mathrm{He}$ gas appears inappropriate for ${ }^{14} \mathrm{C}$ analysis of $\mathrm{EC}$, because charring induces an excess of artificial EC. As 


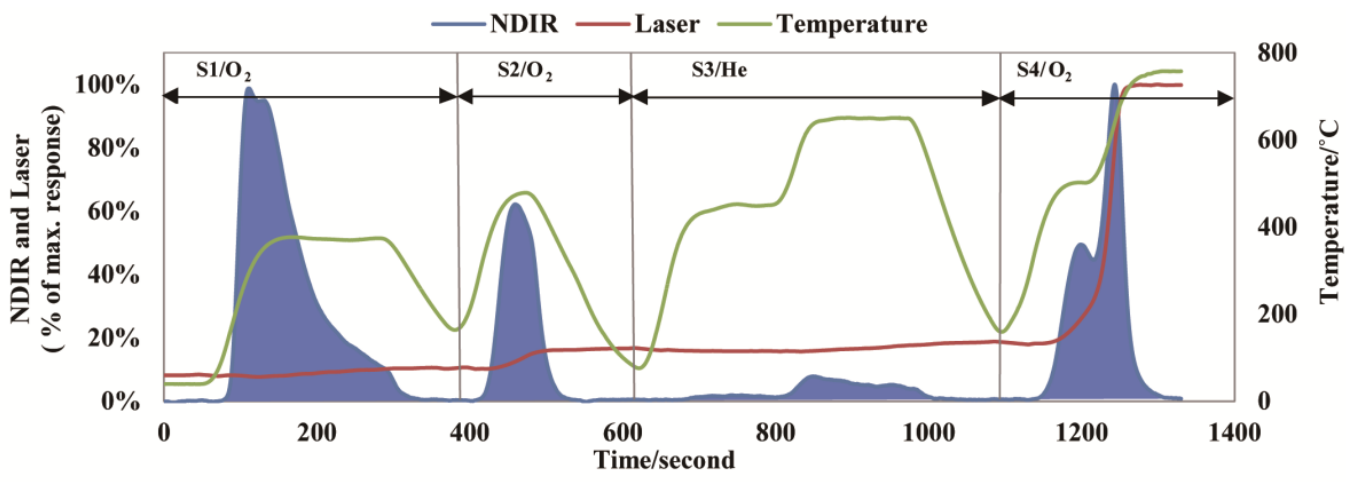

(a)

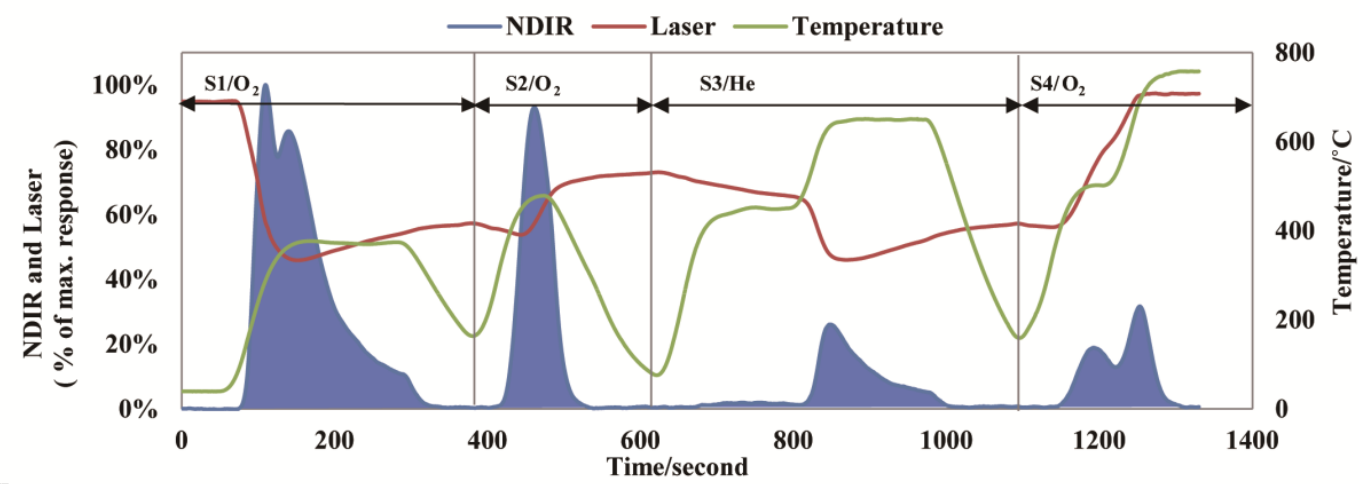

(b)

Fig. 4. Thermograms of a water-extracted aerosol sample (SOL) (a) and its water extract after dropped on a blank filter (b), using the Swiss_4S protocol $\left(\mathrm{S} 2: 475^{\circ} \mathrm{C}, \mathrm{S} 3: 650^{\circ} \mathrm{C}\right)$.

a consequence, the conventional TOA procedures based on OC removal in He (i.e. EUSAAR_2, IMPROVE and NIOSH) cannot be adapted directly to $\mathrm{OC}$ and EC separation for ${ }^{14} \mathrm{C}$ analysis, because it is not clear whether the artificial EC is totally removed before the split point or remains partially on the filter and afterwards evolves together with EC.

The importance of the water-extraction treatment is also underlined by the comparison of the thermograms of a typical aerosol filter and of its WSOC fraction loaded on a blank filter (Fig. 4; for details of the protocol see Sect. 3.2.1). Charring is negligible if analysing the water-extracted aerosols (Fig. 4a), most likely due to the fact that WSOC is susceptible to charring (Yu et al., 2002). The carbon released in the $\mathrm{S} 4$ can consequently be regarded as native EC unaffected by charring and with approximately $75 \%$ EC yield. If the water-soluble portion of $\mathrm{OC}$ is subjected to the same thermal analysis, substantial charring occurs during steps S1-S3 (Fig. 4b) and EC that should not be present is found, indicating that part of the charred OC cannot be removed before S4, and thus is misclassified as EC. Yu et al. (2002) already demonstrated that charring generated from WSOC is indistinguishable from the original aerosol $\mathrm{EC}$ and thus that a fraction of WSOC and EC evolve at the same time. The results confirm the water-extraction treatment is a prerequi- site to isolate $\mathrm{EC}$ for ${ }^{14} \mathrm{C}$ measurement. Although it is not guaranteed that the fractions interfering with EC, including charred carbon fractions and refractory $\mathrm{OC}$, are negligible for all water-extracted samples, they are reduced to acceptable levels with the Swiss_4S protocol. In conclusion, the optimal method to isolate $\mathrm{EC}$ from $\mathrm{TC}$ for ${ }^{14} \mathrm{C}$ measurement should be based on removing $\mathrm{OC}$ in pure oxygen on water-extracted filters before thermal treatments.

\subsection{The Swiss_ 4 S protocol}

\subsubsection{Operational conditions}

The TOA protocol Swiss_4S used in this study employs pure $\mathrm{O}_{2}$ (except in S3) as carrier gas and sets the durations of each temperature step in order to obtain well-resolved carbon peaks with baseline separations (Table 2). The transmittance signal is used for optical monitoring. The operational conditions were optimised to satisfy the following goals: (1) complete decomposition of OC prior to EC collection, (2) negligible charring formation and (3) minimum premature EC evolution.

The peak temperature in $\mathrm{S} 1$ is set to $375^{\circ} \mathrm{C}$ to allow OC removal with least premature EC losses. Although small amounts of refractory organic substances may still not be 
decomposed at this temperature, $375^{\circ} \mathrm{C}$ is a good compromise between the needs of high OC yields and avoiding EC pre-combustion. $\sim 80 \%$ of WINSOC is decomposed in this step. However, the attenuation decrease suggests 1-7\% EC removal during S1, which accounts for up to $3 \%$ uncertainty of $f_{\mathrm{M}}$ of WINSOC. S2 and $\mathrm{S} 3$ are introduced in order to remove remaining refractory OC completely, with minimum EC losses. OC often includes high-molecular-weight compounds (e.g. humic-like substances, HULIS) with a thermal behaviour quite similar to the least refractory EC (Fermo et al., 2006). Iwatsuki et al. (1998) reported that it is necessary to reach a threshold temperature of $485^{\circ} \mathrm{C}$ under pure oxygen for complete removal of these substances. In our experiment, the peak temperature in $\mathrm{S} 2$ is set to a value between $425^{\circ} \mathrm{C}$ and $600^{\circ} \mathrm{C}$ (see Sect. 3.2.2) to remove most of the OC remaining after $\mathrm{S} 1$ with minimum EC losses, thus preventing OC from charring in the following steps. The duration is set to $120 \mathrm{~s}$ to allow different chosen temperatures (from $425^{\circ} \mathrm{C}$ to $600{ }^{\circ} \mathrm{C}$ ) to stay close to the set value for about $20 \mathrm{~s}$. S3 continues with $\mathrm{OC}$ removal in $\mathrm{He}$ and monitors the evolution of any residual OC before switching to the last step (S4). The thermal parameters in S3 are similar to the last two He steps in the conventional TOA protocols (i.e. EUSAAR_2, see Table 2). For a limited number of samples, different peak S3 temperatures were also investigated (see Sect. 3.2.3). Last, $\mathrm{S} 4$ is set to $760^{\circ} \mathrm{C}$ for $150 \mathrm{~s}$, so as to remove all the remaining carbon on the filter. In the following expressions, $f_{\mathrm{M}}(\mathrm{OC})$ and $f_{\mathrm{M}}(\mathrm{EC})$ represent the fraction of modern of the isolated OC (i.e. S1) and EC (i.e. S4), respectively.

\subsubsection{Influence of the $\mathrm{S} 2$ temperature on $\mathrm{OC} / \mathrm{EC}$ separation}

S2 was optimised to remove OC as completely as possible prior to EC collection together with maximum EC recovery in S4. For this, the water-extracted filters were analysed with the peak S2 temperature varying from $425^{\circ} \mathrm{C}$ to $600^{\circ} \mathrm{C}$ with a fixed peak S3 temperature of $650^{\circ} \mathrm{C}$. Figure 5 illustrates the carbon fractions released in each step as a function of peak temperatures in S2. During these analyses, the carbon amounts measured in S1 was found to be reproducible, suggesting a high reproducibility of the water-extraction treatment and the stability of the instrument. At a higher temperature, more refractory OC and non-rEC are lost before $\mathrm{S} 4$, while charring during the analysis is reduced from $6 \%$ to $\sim 0 \%$. Thus, with a higher S2 temperature there is less probability for residues of refractory and charred OC in the final fraction which minimises the bias from the positive artefact (i.e. remaining OC) on the $f_{\mathrm{M}}$ of the $\mathrm{EC}$ recovered in S4. However, the EC yield decreases substantially with increasing $\mathrm{S} 2$ temperature, which also distorts $f_{\mathrm{M}}(\mathrm{EC})$, as this enhances the bias from the negative artefact (i.e. losses of wood-burning EC). Moreover, the higher S2 temperature the lower the EC yield, which directly influences radiocarbon
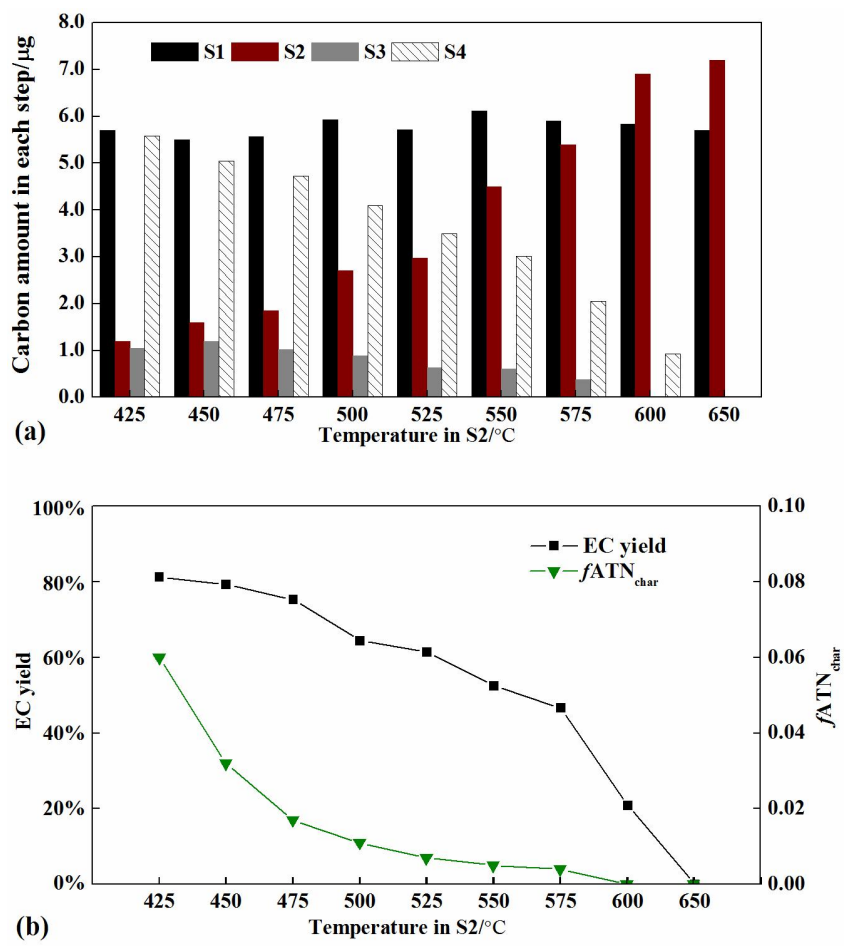

Fig. 5. Carbon amounts released in each step (a) and $f \mathrm{ATN}_{\mathrm{char}}$ and EC yield in S4 (b), as evaluated from analysing a typical waterextracted aerosol sample (ZUR1) by the Swiss_4S protocol with different $\mathrm{S} 2$ temperatures.

measurements of EC in terms of uncertainties and detection limits.

Therefore, the extent of the bias of ${ }^{14} \mathrm{C}$ measurement of EC $\left(\Delta f_{\mathrm{M}}(\mathrm{EC})\right)$ can be estimated as the sum of two contributions:

$\Delta\left(f_{\mathrm{M}}(\mathrm{EC})\right)=\Delta\left(f_{\mathrm{M}}(\mathrm{EC})\right)_{1}+\Delta\left(f_{\mathrm{M}}(\mathrm{EC})\right)_{2}$

where $\Delta f_{\mathrm{M}}(\mathrm{EC})_{1}$ refers to the bias only due to OC charring and pre-combustion of EC, which are considered as the most important factors influencing EC measurement, and $\Delta f_{\mathrm{M}}(\mathrm{EC})_{2}$ refers to the bias from the positive artefact due to the residual OC included in EC step.

Due to the aforementioned artefacts, $\Delta f_{\mathrm{M}}(\mathrm{EC})_{1}$ is dependent on the EC yield and on the percentage of charred carbon $\left(f \mathrm{ATN}_{\text {char }}\right)$ as well as on the $f_{\mathrm{M}}$ of the charred carbon $\left(f_{\mathrm{M}}(\mathrm{char})\right)$ and of the isolated EC in $\mathrm{S} 4\left(f_{\mathrm{M}}(\mathrm{EC})\right)$. As a result, all above factors should be taken into account to calculate $\Delta f_{\mathrm{M}}(\mathrm{EC})_{1}$, as in the below Eq. (7):

$$
\begin{aligned}
& \Delta\left(f_{\mathrm{M}}(\mathrm{EC})\right)_{1}= \\
& \quad \frac{f_{\mathrm{M}}(\mathrm{char}) \times f \mathrm{ATN}_{\text {char }}+f_{\mathrm{M}}(\mathrm{EC}) \times(\text { EC yield })}{\left(f \mathrm{ATN}_{\text {char }}+(\text { EC yield })\right) \times f_{\mathrm{M}}(\mathrm{EC})}-1
\end{aligned}
$$

$\Delta f_{\mathrm{M}}(\mathrm{EC})_{1}$ can be reduced to less than $\sim 5 \%$ if the peak $\mathrm{S} 2$ temperature is higher than $450{ }^{\circ} \mathrm{C}$, assuming that the ${ }^{14} \mathrm{C}$ content of charred carbon is three times as much as that in 

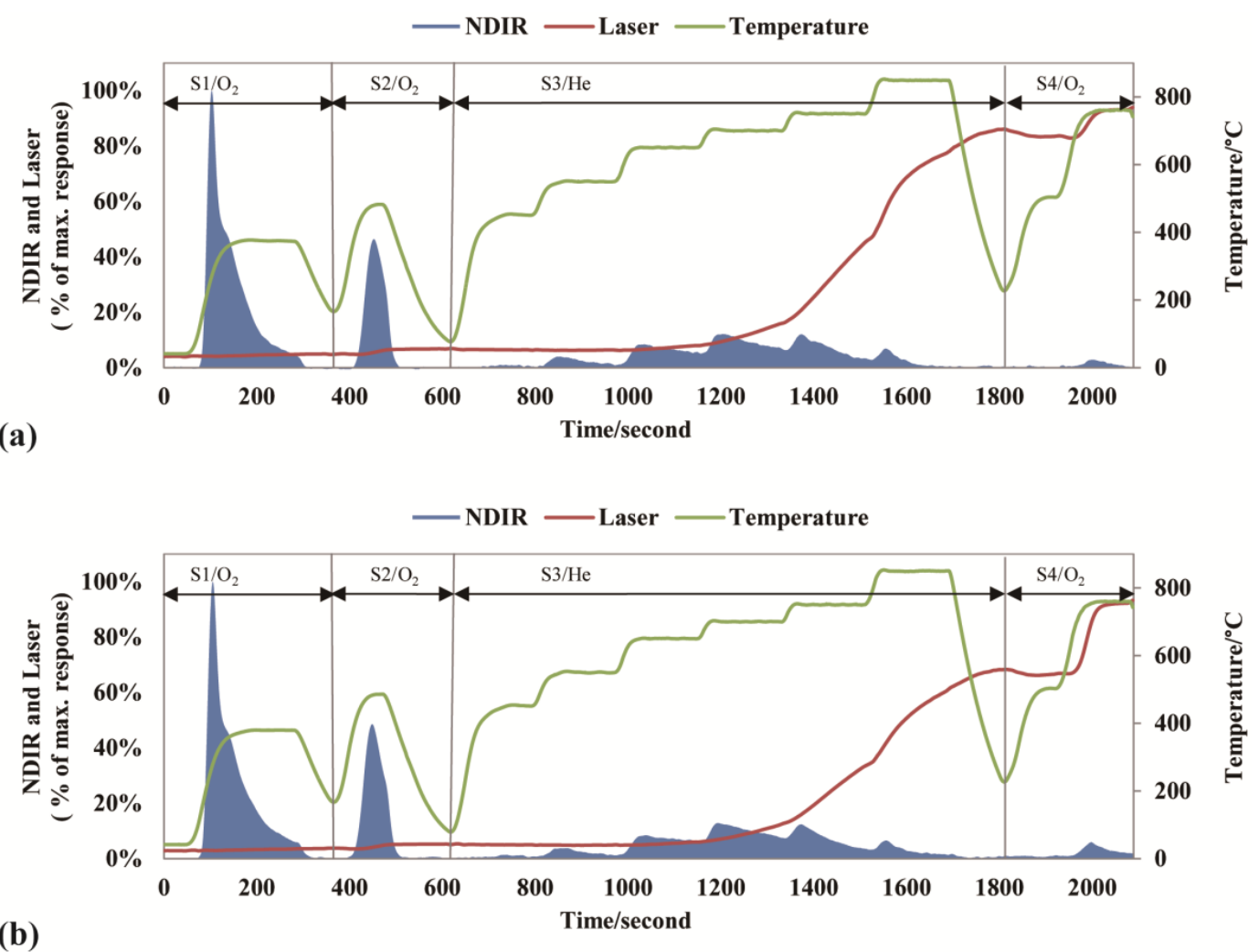

Fig. 6. Thermograms from the analysis of two water-extracted winter samples CHI (a), and MOL (b). The protocol used for analysis was modified according to the Swiss_4S protocol (see in Table 2) with a fixed peak S2 temperature of $475^{\circ} \mathrm{C}$, but with different steps in S3 (He mode): $450{ }^{\circ} \mathrm{C}, 550{ }^{\circ} \mathrm{C}, 650{ }^{\circ} \mathrm{C}, 700^{\circ} \mathrm{C}, 750^{\circ} \mathrm{C}$ and $850{ }^{\circ} \mathrm{C}$, each of $180 \mathrm{~s}$.

$\mathrm{EC}\left(\right.$ e.g. $f_{\mathrm{M}}($ charred $\left.\mathrm{OC})=0.6, f_{\mathrm{M}}(\mathrm{EC})=0.2\right)$, which is reasonable as indicated below in Sect. 3.4. Consequently, as the most satisfying compromise between complete evolution of OC and a minimum EC pre-combustion before EC collection, $475^{\circ} \mathrm{C}$ is chosen as the peak $\mathrm{S} 2$ temperature in the Swiss_4S protocol. With this S2 temperature, both charring and pre-combustion of EC are kept at acceptable levels. However, this temperature can be increased up to $525^{\circ} \mathrm{C}$ in order to guarantee complete OC removal before $\mathrm{S} 4$, which may become necessary for a few filters with high OC loading. By analysis of such samples, we observed that EC yields $>90 \%$ after $\mathrm{S} 2$ and/or $f \mathrm{ATN}_{\text {char }}>10 \%$ during the analysis, increasing the risk of remaining OC in the EC step (i.e. S4). This risk can be much reduced by increasing the peak $\mathrm{S} 2$ temperature from $475^{\circ} \mathrm{C}$ to maximum $525^{\circ} \mathrm{C}$.

\subsubsection{Influence of the $\mathrm{S3}$ temperature on $\mathrm{OC} / \mathrm{EC}$ separation}

S3 is carried out in helium to remove OC completely before isolation and collection of EC during S4. Previous studies have demonstrated that the OC/EC split can be strongly influenced by the peak temperature step in He mode (Conny et al., 2003). Some certain types of OC such as wood smoke do not completely evolve or pyrolyse at low inert-mode temperatures (Novakov and Corrigan, 1995), while the combustion of some EC can be catalytically enhanced by the presence of mineral oxides at high inert-mode temperatures (Fung, 1990). In order to minimise $\Delta f_{\mathrm{M}}(\mathrm{EC})_{2}$ (Eq. 6), we examined the effect of the peak He temperature (i.e. S3) on the carbon amounts and the ${ }^{14} \mathrm{C}$ content of isolated EC in S4 $\left(f_{\mathrm{M}}(\mathrm{EC})\right)$. The protocol used for analysis was modified according to the Swiss_4S protocol (see Table 2) with a fixed peak S2 temperature of $475^{\circ} \mathrm{C}$, but with different intermediate steps in $\mathrm{S} 3$ (He mode): $450^{\circ} \mathrm{C}, 550^{\circ} \mathrm{C}, 650^{\circ} \mathrm{C}, 700^{\circ} \mathrm{C}$, $750^{\circ} \mathrm{C}$ and $850^{\circ} \mathrm{C}$, each of $180 \mathrm{~s}$. Figure $6 \mathrm{a}$ and $\mathrm{b}$ show two typical thermograms obtained by analysing two rural winter samples (MOL and CHI, see Table 1) with considerable contributions from wood burning (Szidat et al., 2007). The transmission signal remains quite stable from $450^{\circ} \mathrm{C}$ to $550^{\circ} \mathrm{C}$ in $\mathrm{S} 3$ and begins increasing slightly when the temperature reaches $650^{\circ} \mathrm{C}$. This shows that carbon evolving below $550^{\circ} \mathrm{C}$ is exclusively OC, without any untimely removal of EC. The carbon evolved between $550^{\circ} \mathrm{C}$ to $650^{\circ} \mathrm{C}$ in $\mathrm{S} 3$ can be either pure $\mathrm{EC}$ or a combination of $\mathrm{EC}$ and remaining $\mathrm{OC}$. Then, after temperature exceeds $700^{\circ} \mathrm{C}$, the transmission signals increases rapidly, indicating substantial premature EC removal. This phenomenon is not only found for these two 
samples, but also in many other winter samples with large wood-burning contributions (data not shown here). The EC evolving in He during high temperature steps can be either native EC or charred carbon, or a combination of them (Subramanian et al., 2006). However, as the charring is negligible in our method, the transmittance increasing in S3 can only be explained by premature EC losses. Indeed, EC may be catalytically removed by mineral oxides under inert gas conditions even at lower high temperature (Fung, 1990; Wang et al., 2010). In the Swiss_4S protocol, more metal oxides may form upon heating in the presence of pure oxygen in $\mathrm{S} 1$ and $\mathrm{S} 2$, which may enhance the premature EC losses in S3.

The EC optical yield at $650^{\circ} \mathrm{C}$ is about $45 \%$ and $20 \%$ higher than at $850^{\circ} \mathrm{C}$ and $700^{\circ} \mathrm{C}$, respectively. As a result, lowering the peak $\mathrm{S} 3$ temperature below $850^{\circ} \mathrm{C}$ can improve the EC recovery substantially by avoiding premature EC losses, and thus ${ }^{14} \mathrm{C}$ results obtained from collected $\mathrm{EC}$ in S4 could represent the entire EC better. However, the lower the peak S3 temperature, the higher the possibilities that OC might not totally be removed before $\mathrm{S} 4$, so the complete OC removal at a low peak $\mathrm{S} 3$ temperature needs to be confirmed. To evaluate a possible bias due to different peak S3 temperatures, samples were analysed by the Swiss_4S protocol with a fixed maximum $\mathrm{S} 2$ temperature of $475^{\circ} \mathrm{C}$, but with different peak S3 (He mode) temperatures of $550^{\circ} \mathrm{C}, 650^{\circ} \mathrm{C}$ and $700{ }^{\circ} \mathrm{C}$. Additionally, ${ }^{14} \mathrm{C}$ measurements of the $\mathrm{CO}_{2}$ collected during $\mathrm{S} 4$ are also carried out for the samples SOL, MOL and CHI. As illustrated in Fig. 7, $f_{\mathrm{M}}(\mathrm{EC})$ and EC yields decrease by $\sim 15 \%$ and $\sim 10 \%$ respectively, when the peak S3 temperature increases from $550^{\circ} \mathrm{C}$ to $650^{\circ} \mathrm{C}$. This result implies that a fraction of OC may evolve even after S3 with too low a peak S3 temperature (i.e. $550{ }^{\circ} \mathrm{C}$ ) and is erroneously collected together with native $\mathrm{EC}$ in $\mathrm{S} 4$, which leads to a positive bias of $f_{\mathrm{M}}(\mathrm{EC})$. Recently, Cavalli et al. (2010) also observed that $\mathrm{OC}$ can evolve into $\mathrm{He} / \mathrm{O}_{2}$ step with a peak He temperature of $550^{\circ} \mathrm{C}$ such as IMPROVE, thus potentially overestimating EC. However, when the peak S3 temperature is increased from $650^{\circ} \mathrm{C}$ to $700{ }^{\circ} \mathrm{C}, f_{\mathrm{M}}(\mathrm{EC})$ does not decrease significantly, while an obvious $(\sim 25 \%)$ EC yield decrease occurs, corresponding to $\sim 5 \%$ uncertainty on the attribution of EC to non-fossil sources. Supposing that the $f_{\mathrm{M}}(\mathrm{EC})$ measured at a peak S3 temperature of $700{ }^{\circ} \mathrm{C}$ represents the "true" $f_{\mathrm{M}}(\mathrm{EC})$ value, the bias of $f_{\mathrm{M}}(\mathrm{EC})\left(\Delta f_{\mathrm{M}}(\mathrm{EC})_{2}\right)($ Eq. 6, in Sect. 3.2.2) at a peak $\mathrm{S} 3$ temperature of $550^{\circ} \mathrm{C}$ and $650{ }^{\circ} \mathrm{C}$ imply $\sim 25 \%$ and $\sim 5 \%$ contaminations to $\mathrm{EC}$, respectively, resulting from $\mathrm{OC}$ remaining after S3. However, the higher ${ }^{14} \mathrm{C}$ values of EC obtained with a lower peak $\mathrm{S} 3$ temperature (i.e. $550^{\circ} \mathrm{C}$ and $650^{\circ} \mathrm{C}$ ) could also stem from a better recovery of the biomass-burning EC. In these circumstances, $\sim 25 \%$ and $\sim 5 \%$ may be the upper limits for OC contamination in native EC at peak S3 temperatures of $550^{\circ} \mathrm{C}$ and $650{ }^{\circ} \mathrm{C}$, respectively. The results demonstrate that the carbon evolving between $650^{\circ} \mathrm{C}$ and $700^{\circ} \mathrm{C}$ during $\mathrm{S} 3$ is almost exclusively native $\mathrm{EC}$ with a maximum $5 \%$ OC contamination, corresponding to an accepted uncer-
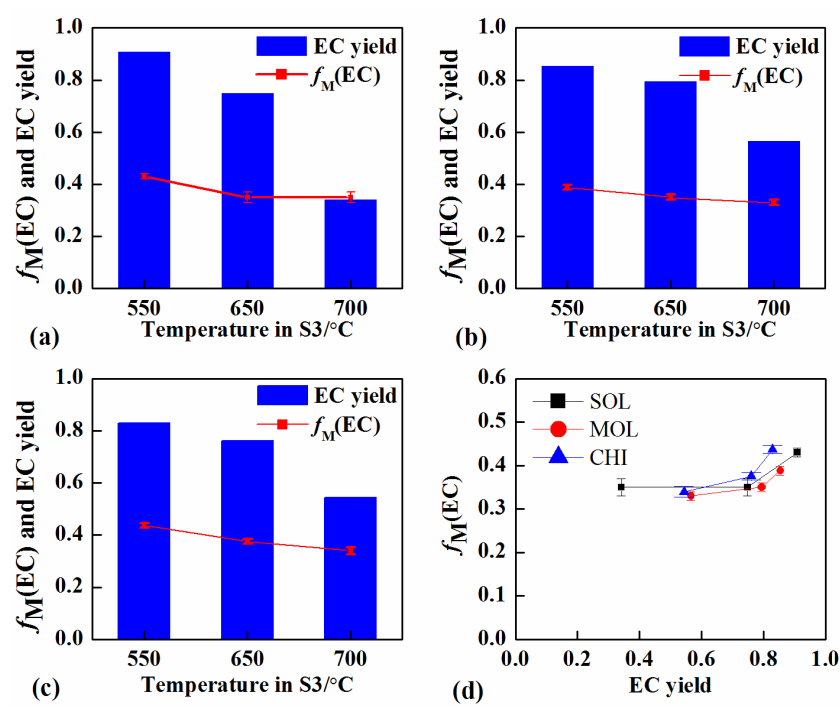

Fig. 7. Influence of S3 temperatures in the Swiss_4S protocol on EC yields and fraction of modern of recovered EC in S4 $\left(f_{\mathrm{M}}(\mathrm{EC})\right)$ from the analysis of the water-extracted winter samples SOL (a), MOL (b) and CHI (c) and $f_{\mathrm{M}}(\mathrm{EC})$ as a function of different EC yields (d).

tainty $(<5 \%)$ in $f_{\mathrm{M}}(\mathrm{EC})$. Therefore, $650^{\circ} \mathrm{C}$ is selected as the peak temperature in $\mathrm{S} 3$, the same as the maximum $\mathrm{He}$ temperature in the EUSAAR_2 protocol, which assures that the bias of $f_{\mathrm{M}}(\mathrm{EC})$ due to the positive artefact (i.e. the residual OC slipping into the EC step) is minimised (less than $5 \%$ ) with a maximum EC yield. However, this temperature may be decreased down to $550^{\circ} \mathrm{C}$ for filters, which show substantial EC losses in S3, e.g. due to premature EC evolution caused by catalytic oxidation in the presence of mineral dust (Fung, 1990; Wang et al., 2010). For such samples, we suggest that EC yields should not be lower than $\sim 60 \%$, which may be avoided by decreasing the S3 temperature from $650^{\circ} \mathrm{C}$ to minimum $550^{\circ} \mathrm{C}$. In general, the EC recovery amounts to maximum $70-90 \%$ in this work, so that the source apportionment of the entire EC is still not quantitative if only EC in S4 is considered.

\subsubsection{Comparison of TC, OC and EC concentrations from Swiss_4S with EUSAAR_2}

A few particulate matter samples were also analysed by the protocol EUSAAR_2 to perform a first comparison with the present protocol Swiss_4S results on TC, OC and EC concentrations. All filters were water-extracted before their OC/EC determinations. The EC amounts measured by the Swiss_4S protocol was corrected to $100 \%$ EC yield, and OC was determined by subtraction of the corrected EC from TC. In general, Fig. 8a, b and c show a very good agreement between both protocols for all fractions, which suggests that the Swiss_4S protocol provide reliable concentrations of OC and EC. Piazzalunga et al. (2011) also demonstrated that the 


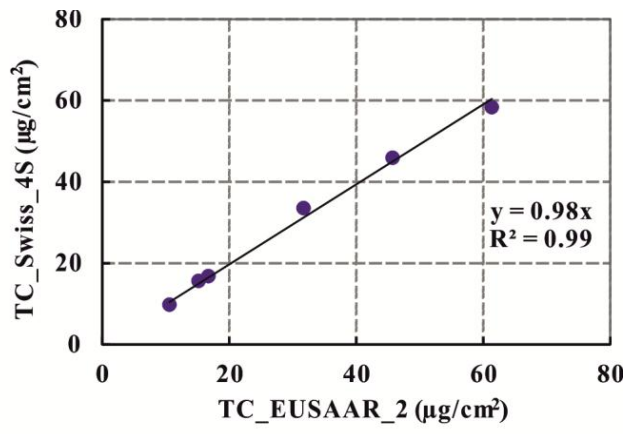

(a)

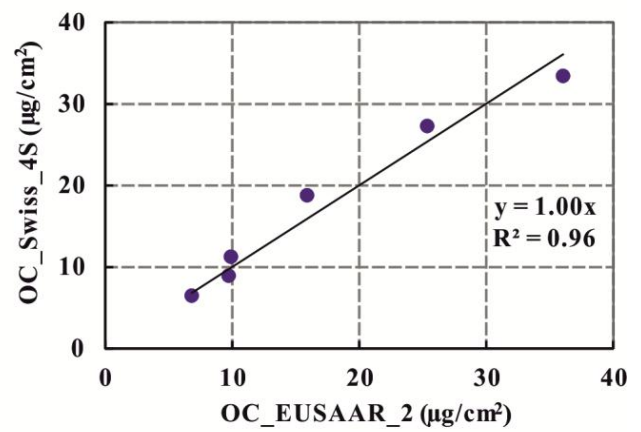

(b)

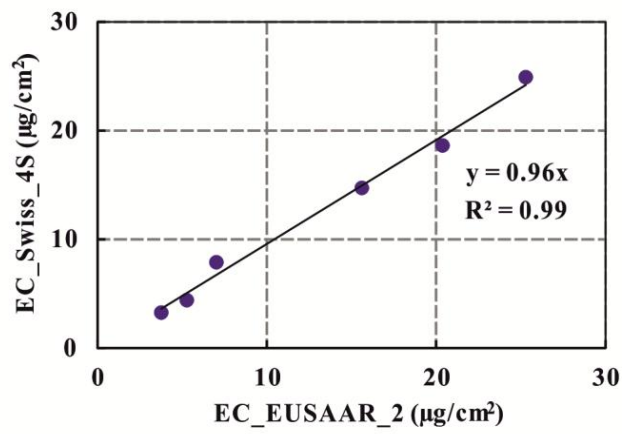

(c)

Fig. 8. Comparisons between the Swiss_4S and EUSAAR2 protocols for the analysis of TC (a), OC (b) and EC (c) for the waterextracted aerosol samples.

removal of water-soluble compounds from the filter is effective in reducing the differences between different protocols. A more rigorous comparison on a larger number of samples is currently in progress at our laboratory.

\subsection{Comparison of ${ }^{14} \mathrm{C}$ results using the Swiss_4S protocol and the THEODORE method}

A comparison of the Swiss_4S protocol and the THEODORE method was performed for a few selected filters from the Göteborg 2005/2006 campaign (Szidat et al., 2009). For both methods, OC and EC were recovered on original and waterextracted filters, respectively. The OC concentrations show differences between both methods within $<15 \%$ without any trend (Table 3). Nevertheless, there is no significant dif- ference of the corresponding $f_{\mathrm{M}}(\mathrm{OC})$. Concerning $\mathrm{EC}$, the premature losses of EC during the OC removal before collecting $\mathrm{CO}_{2}$ increase with increasing peak $\mathrm{S} 2$ temperatures in the Swiss_4S protocol and the oven temperatures used in the previous THEODORE method (Fig. 9). For both methods, the decrease in $f_{\mathrm{M}}(\mathrm{EC})$ is linearly associated with the decreasing EC yields. This confirms that non-fossil EC is less refractory than fossil EC, suggesting that the recovered EC cannot fully represent the total EC. Figure 9 also reveals that both methods underestimate the wood-burning contribution, unless the complete EC fraction is taken into account for source apportionment and that the bias increases with decreasing EC recoveries. For this sample (GOT2), a range of $\sim 35 \%$ to $\sim 90 \%$ EC yield leads to a difference of $\sim 0.15$ for $f_{\mathrm{M}}(\mathrm{EC}) . f_{\mathrm{M}}$ of the total EC is estimated by linear extrapolation to $100 \%$ EC yields as $0.22 \pm 0.01$ and $0.19 \pm 0.02$ ( $1 \sigma$ uncertainties) for the Swiss_4S and the THEODORE methods, respectively. It is speculated that the different fossil and non-fossil contributions in EC may result in a continuum from thermally refractory near-elemental EC to thermally reactive or non-refractory EC.

However, $f_{\mathrm{M}}(\mathrm{EC})$ has not been found to decrease significantly with decreasing EC yields when the different peak $\mathrm{S} 3$ (He mode) temperature increases from $650^{\circ} \mathrm{C}$ to $700^{\circ} \mathrm{C}$ (Fig. 7). This most likely arises from the more rigorous OC removing treatments in an oxidative atmosphere (i.e. $\mathrm{S} 2$ in Swiss_4S and oven in THEODORE method) compared to an inert atmosphere (i.e. S3 in Swiss_4S), which may enhance the different behaviour of wood-burning EC compared to fossil EC and favour its untimely removal.

\subsection{The optimal strategy of radiocarbon-based source apportionment of carbonaceous aerosols}

\subsubsection{Considerations of total EC}

According to the separation scheme shown in Fig. 2, different carbon fractions of two aerosol samples (GOT2 and GOT3) were isolated for ${ }^{14} \mathrm{C}$ determination using the Swiss_4S protocol. As illustrated in Fig. $10,{ }^{14} \mathrm{C}$ measurements of the individual different carbon fractions (i.e. OC, EC, WINSOC and WSOC) may provide more comprehensive and refined information for source apportionment of carbonaceous aerosols. The distinction between WSOC and WINSOC shows a significantly higher fossil contribution for the water-insoluble fraction. WSOC is nearly on the contemporary level, suggesting that secondary organic aerosol (SOA) is mainly formed from biogenic VOCs in the studied area, as WSOC aerosol is thought to be a good proxy for SOA (Weber et al., 2007; Jimenez et al., 2009). Consequently, OC should be separated into WSOC and WINSOC fractions to better understand its sources.

Moreover, the experiments above demonstrate the lower refractivity of wood-burning EC compared to fossil EC and the difficulty of clearly isolating EC without premature 
Table 3. Comparisons of the carbon masses $(m(\mathrm{OC}))$ and fraction of modern of $\mathrm{OC}\left(f_{\mathrm{M}}(\mathrm{OC})\right)$ obtained with the present thermal-optical method (Swiss_4S) and thermal method (THEODORE).

\begin{tabular}{lccccc}
\hline \multirow{2}{*}{ Sample } & \multicolumn{2}{c}{ Swiss_4S } & & \multicolumn{2}{c}{ THEODORE } \\
\cline { 2 - 3 } \cline { 5 - 6 } & $m(\mathrm{OC}) \mu \mathrm{g} \mathrm{cm}^{-2}$ & $f_{\mathrm{M}}(\mathrm{OC})$ & & $m(\mathrm{OC}) \mu \mathrm{g} \mathrm{cm}^{-2}$ & $f_{\mathrm{M}}(\mathrm{OC})$ \\
\hline GOT1 & $13.7 \pm 0.4$ & $0.74 \pm 0.02$ & & $15.7 \pm 0.4$ & $0.74 \pm 0.02$ \\
GOT2 & $61.6 \pm 1.3$ & $0.64 \pm 0.01$ & & $54.8 \pm 1.5$ & $0.67 \pm 0.02$ \\
GOT3 & $19.4 \pm 0.4$ & $0.72 \pm 0.01$ & & $19.6 \pm 0.5$ & $0.73 \pm 0.01$ \\
\hline
\end{tabular}

Table 4. EC yield and fraction of modern $\left(f_{\mathrm{M}}\right)$ of the refractory EC (rEC), non-refractory EC (non-rEC) and total EC (tEC).

\begin{tabular}{lcccc}
\hline Sample & $f_{\mathrm{M}}(\mathrm{rEC})^{\mathrm{a}}$ & $f_{\mathrm{M}}{\text { (non-rEC })^{\mathrm{b}}}$ & $f_{\mathrm{M}}(\mathrm{tEC})^{\mathrm{b}}$ & $\begin{array}{c}\text { EC yield } \\
\mathrm{rEC} / \mathrm{tEC}\end{array}$ \\
\hline GOT2 & $0.17 \pm 0.01$ & $0.23 \pm 0.07$ & $0.18 \pm 0.04$ & $0.80 \pm 0.06$ \\
GOT3 & $0.18 \pm 0.01$ & $0.27 \pm 0.08$ & $0.19 \pm 0.04$ & $0.76 \pm 0.06$ \\
SOL & $0.33 \pm 0.01$ & $0.42 \pm 0.06$ & $0.35 \pm 0.06$ & $0.74 \pm 0.05$ \\
ZUR3 & $0.28 \pm 0.01$ & $0.58 \pm 0.06$ & $0.35 \pm 0.06$ & $0.77 \pm 0.05$ \\
MAG & $0.38 \pm 0.01$ & $0.56 \pm 0.07$ & $0.42 \pm 0.04$ & $0.80 \pm 0.05$ \\
BER & $0.22 \pm 0.01$ & $0.35 \pm 0.06$ & $0.24 \pm 0.04$ & $0.85 \pm 0.04$ \\
SIS & $0.30 \pm 0.01$ & $0.36 \pm 0.06$ & $0.31 \pm 0.06$ & $0.82 \pm 0.05$ \\
\hline
\end{tabular}

a rEC: refractory EC as the isolated EC during S4 in the Swiss_4S protocol

$\mathrm{b}$ non-rEC: non-refractory EC as the EC fractions in $\mathrm{S} 2$ and $\mathrm{S} 3$ in the Swiss_4S protocol

${ }^{c}$ tEC: total $\mathrm{EC}=\mathrm{rEC}+$ non-rEC

evolution of EC. For an optimal ${ }^{14} \mathrm{C}$-based source apportionment of carbonaceous aerosols, and particularly of EC, the whole amount of EC has to be taken into account to quantify its fossil vs. non-fossil contributions. Indeed, total EC (tEC) consists not only of $\mathrm{rEC}$ recovered in $\mathrm{S} 4$, but also of non-rEC evolved in S2 and S3. Therefore, not only the characteristic of the rEC in S4, but also that of non-rEC evolving during S2 and S3 should be investigated. As shown in Figs. 2 and 10, the most refractory WINSOC and non-rEC, which are volatilized simultaneously due to their overlapping thermal properties, can also be recovered for ${ }^{14} \mathrm{C}$ analysis. To estimate the ${ }^{14} \mathrm{C}$ content of non-rEC from this mixture, we determined $\mathrm{OC}$ and $\mathrm{EC}$ filter concentrations using the EUSAAR_2 protocol and assumed that the refractory WINSOC has the same ${ }^{14} \mathrm{C}$ value (within $5 \%$ uncertainty) as the WINSOC from S1.

Following this isotope-mass balance, $f_{\mathrm{M}}$ (non-rEC) amounts to $0.23 \pm 0.07$ and $0.27 \pm 0.08$ for the GOT2 and GOT3 samples, respectively. This is $\sim 30 \%$ higher than the $f_{\mathrm{M}}(\mathrm{rEC})$ measured from $\mathrm{S} 4(0.17 \pm 0.01$ and $0.18 \pm 0.01$, respectively). Correspondingly, $f_{\mathrm{M}}(\mathrm{tEC})$ amounts to $0.18 \pm 0.04$ and $0.19 \pm 0.04$, respectively for these two samples, which is $\sim 6 \%$ higher than the corresponding $f_{\mathrm{M}}(\mathrm{rEC})$. Similar results are also found for the other samples shown in Table 4. Moreover, for the GOT2 sample analysed with the Swiss_4S protocol and the THEODORE method, the $f_{\mathrm{M}}(\mathrm{tEC})$ values from the isotope-mass balance are consistent, within uncertainties, with the extrapolations

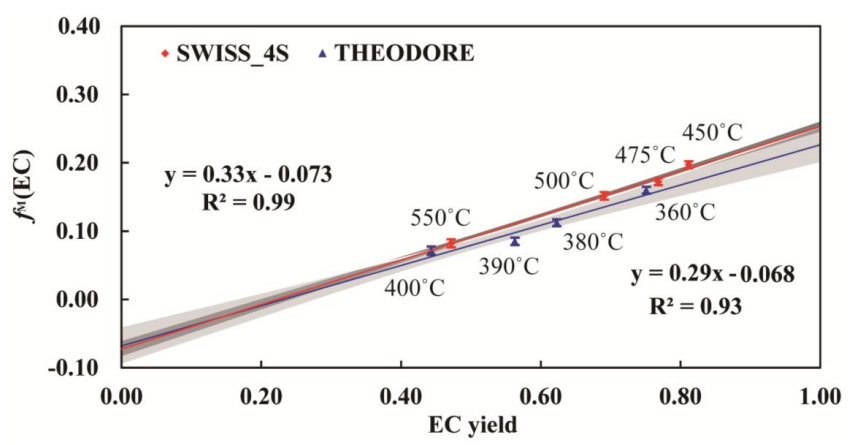

Fig. 9. $f_{\mathrm{M}}(\mathrm{EC})$ in $\mathrm{S} 4$ as a function of EC yield obtained by analysing the sample GOT2 with the Swiss_4S protocol and the previously used THEODORE method with different peak S2 temperatures and the oven temperatures, respectively. Shading indicates the confidential interval of the linear extrapolation within $1 \sigma$.

to the corresponding $100 \%$ EC yield (Fig. 9). Although the deviations of the ${ }^{14} \mathrm{C}$ determinations of $\mathrm{rEC}$ and $\mathrm{tEC}$ are not statistically significant for the individual samples, Figs. 9, 10 and Table 4 suggest a general trend towards an underestimation of EC from wood and/or biomass burning for both methods. As shown above, this trend strongly depends on the EC recovery and, moreover, probably on the sample types. Therefore, refractory WINSOC and non-rEC (S2 and S3), as well as OC (S1) and rEC (S4), should also be isolated with the Swiss_4S protocol for subsequent ${ }^{14} \mathrm{C}$ measurements, at least for a few selected samples from a dedicated campaign, in order to get a comprehensive picture of the fossil and contemporary sources of carbonaceous aerosols (see Fig. 10). As for the solely thermal methods (i.e. the THEODORE method), the $f_{\mathrm{M}}$ value of total EC may be derived from measurements of $f_{\mathrm{M}}(\mathrm{EC})$ for different oven temperatures and the extrapolation to $100 \% \mathrm{EC}$ yield for selected samples similar to Fig. 9 (see Fig. S1). Moreover, we recommend that ${ }^{14} \mathrm{C}$ results of EC should in general be reported together with the EC recovery, because the recovered EC may not fully represent the total EC. This procedure also avoids possible discrepancies between temperatures as displayed by the oven from actual temperatures on the filter. In the Supplement (Figs. S1, S2, Table S1 and Sect. S1), we compile EC yields of $f_{\mathrm{M}}(\mathrm{EC})$ determinations from earlier studies (Szidat et al., 2004b, 2006, 2007, 2009; Sandradewi 

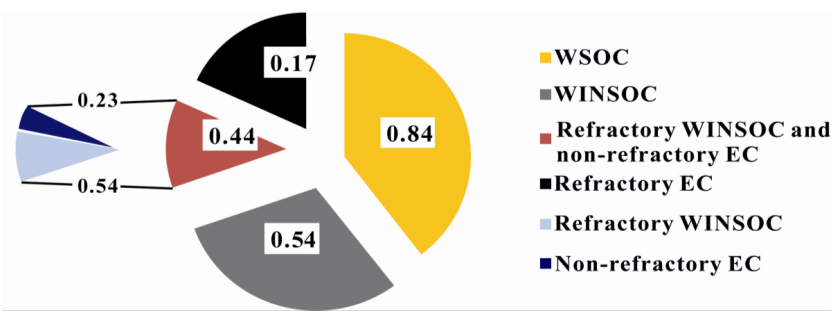

(a)

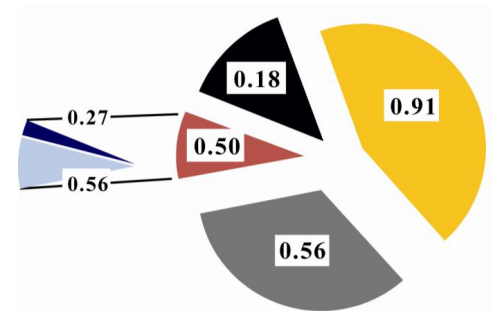

$\because$ WSOC -WINSOC

Refractory WINSOC and

non-refractory EC

-Refractory EC

Refractory WINSOC

-Non-refractory EC

(b)

Fig. 10. Composition of different carbonaceous particle fractions (pies) and $f_{\mathrm{M}}$ values (numbers) in Göteborg for winter (GOT2) (a) and summer (GOT3) (b).

et al., 2008a, b; Aiken et al., 2009; Hodzic et al., 2010; Minguillón et al., 2011; Perron et al., 2010) with estimations of $f_{\mathrm{M}}$ values of total $\mathrm{EC}\left(f_{\mathrm{M}}(\mathrm{tEC})\right)$ by extrapolation to $100 \%$ EC yield. Overall, fossil EC could be overestimated by $5-70 \%$ with an average of $30 \pm 15 \%$ (Table S1) if only rEC was taken into account to quantify relative fossil and non-fossil contributions of EC.

\subsubsection{Mass closure for $\mathrm{OC}$}

For ${ }^{14} \mathrm{C}$ measurement of $\mathrm{OC}$, untreated filters were analysed with the Swiss $4 \mathrm{~S}$ protocol and the $\mathrm{CO}_{2}$ evolving from $\mathrm{S} 1$ (accounting for $75 \sim 85 \%$ of total OC) was recovered. The unrecovered $\mathrm{OC}$ can correspond to charred $\mathrm{OC}$ formed during $\mathrm{S} 1$ and to refractory $\mathrm{OC}$ which cannot be released under $\mathrm{S} 1$ temperature $\left(375^{\circ} \mathrm{C}\right)$. Using the isotope-mass balance (total OC $=$ WSOC + non-refractory WINSOC + refractory WINSOC), the $f_{\mathrm{M}}$ values of total OC are calculated to be $0.86 \pm 0.02$ and $0.74 \pm 0.02$ for samples MOL and GOT3, respectively. These values are consistent with the values measured from $\mathrm{OC}$ isolated in S1, i.e. $0.88 \pm 0.01$ and $0.72 \pm 0.01$, respectively. This suggests that charring and unevolved refractory OC during S1 do not alter the ${ }^{14} \mathrm{C}$ signatures of the total OC significantly. However, this should be evaluated carefully for each sample, particularly if the loading of OC is too low or the amount of charred OC is too high.

\section{Conclusions}

A detailed study has been performed to establish a new thermal-optical protocol to isolate the carbon fractions of interest (i.e. OC and EC) for ${ }^{14} \mathrm{C}$ measurement. To min-

imise OC charring, untimely removal of EC and the potential positive artefacts leading to co-evolution of $\mathrm{EC}$ with residual OC, the Swiss_4S protocol has been developed by optimising thermal-optical conditions, in particular the heating program and the choice of the carrier gas. This optimised Swiss_4S protocol involves the following consecutive four steps: (1) $\mathrm{S} 1$ in $\mathrm{O}_{2}$ at $375^{\circ} \mathrm{C}$ for isolation of $\mathrm{OC}$ (untreated filters) or WINSOC (water-extracted filters) without premature EC evolution; (2) $\mathrm{S} 2$ in $\mathrm{O}_{2}$ at $475^{\circ} \mathrm{C}$ followed by (3) $\mathrm{S} 3$ in $\mathrm{He}$ at $650^{\circ} \mathrm{C}$, the same as the peak temperature in the EUSAAR 2 protocol; and (4) $\mathrm{S} 4$ in $\mathrm{O}_{2}$ at $760^{\circ} \mathrm{C}$ for recovering the remaining EC. For few special samples, these parameters may need to be optimised: the $\mathrm{S} 2$ peak temperature may be increased up to $525^{\circ} \mathrm{C}$ for filters with high OC loading in order to make sure that $\mathrm{OC}$ is removed completely before $\mathrm{S} 4$; the $\mathrm{S} 3$ peak temperature may be decreased down to $550^{\circ} \mathrm{C}$ for samples with an extraordinary mineral-dust contribution in order to prevent too large EC losses before S4. It is noteworthy that the water-extraction treatment prior to any thermal treatment is an essential prerequisite for EC isolation and its subsequent radiocarbon analysis, as this substantially reduces charring by removal of water-soluble organic and inorganic compounds. Otherwise the non-fossil contribution due to the positive bias from charring could be potentially overestimated. A good agreement on OC and EC concentrations has been found between the Swiss_4S and the EUSAAR_2 protocols applied to some water-extracted samples.

The ${ }^{14} \mathrm{C}$ analysis of isolated $\mathrm{OC}$ from $\mathrm{S} 1$ and $\mathrm{EC}$ from S4 using the Swiss_4S protocol concerns $\sim 80 \%$ of total OC and total EC, which already gives a good indication of the OC and EC sources. However, the full information about all the emissions cannot be based on ${ }^{14} \mathrm{C}$ analysis of OC and EC only. On the one hand, OC should be separated into WSOC and WINSOC fractions to better understand its sources, because the water-insoluble fraction has a significantly higher fossil contribution. On the other hand, due to the lower refractivity of biomass-burning EC compared to fossil EC, the former fraction partially co-evolve with refractory OC during thermal treatment. Therefore, ${ }^{14} \mathrm{C}$ analysis of $\mathrm{EC}$ in $\mathrm{S} 4$ alone may underestimate the wood-burning contribution, and thus a simplified technique of complete EC isolation for ${ }^{14} \mathrm{C}$ analysis is not optimal. Consequently, the best strategy for radiocarbon-based source apportionment of carbonaceous aerosols involves a subdivision of TC into carbon fractions of different chemical and physical properties. To better perform ${ }^{14} \mathrm{C}$-based source apportionment of carbonaceous aerosols, the Swiss_4S protocol is implemented to determine the ${ }^{14} \mathrm{C}$ content not only in $\mathrm{OC}$ and $\mathrm{rEC}$ fractions but also WINSOC as well as a continuum of refractory OC and non-rEC. In addition, WSOC can be determined by subtraction of the water-soluble fraction of TC from untreated TC. For the solely thermal methods (i.e. the THEODORE method), the $f_{\mathrm{M}}$ value of total EC can be derived from measurements of $f_{\mathrm{M}}(\mathrm{EC})$ for different oven temperatures durations and the extrapolation to $100 \%$ EC yield for selected 
samples. Moreover, we recommend that ${ }^{14} \mathrm{C}$ results of $\mathrm{EC}$ should in general be reported together with the EC yield.

\section{Supplementary material related to this article is available online at: http://www.atmos-chem-phys.net/12/ 10841/2012/acp-12-10841-2012-supplement.zip.}

Acknowledgements. This work was supported by the Swiss Federal Office for the Environment (FOEN) and the Swiss Cantons Solothurn, Ticino and beider Basel. M. C. Minguillón was funded by the Spanish Programa Nacional de Movilidad de Recursos Humanos del Plan Nacional de I-D+I 2008-2011 and by the JAE-Doc CSIC program, co-funded by the European Social Fund (ESF).

Edited by: N. M. Donahue

\section{References}

Aiken, A. C., Salcedo, D., Cubison, M. J., Huffman, J. A., DeCarlo, P. F., Ulbrich, I. M., Docherty, K. S., Sueper, D., Kimmel, J. R., Worsnop, D. R., Trimborn, A., Northway, M., Stone, E. A., Schauer, J. J., Volkamer, R. M., Fortner, E., de Foy, B., Wang, J., Laskin, A., Shutthanandan, V., Zheng, J., Zhang, R., Gaffney, J., Marley, N. A., Paredes-Miranda, G., Arnott, W. P., Molina, L. T., Sosa, G., and Jimenez, J. L.: Mexico City aerosol analysis during MILAGRO using high resolution aerosol mass spectrometry at the urban supersite (T0) - Part 1: Fine particle composition and organic source apportionment, Atmos. Chem. Phys., 9, 6633-6653, doi:10.5194/acp-9-6633-2009, 2009.

Andreae, M. O. and Gelencsér, A.: Black carbon or brown carbon? The nature of light-absorbing carbonaceous aerosols, Atmos. Chem. Phys., 6, 3131-3148, doi:10.5194/acp-6-3131-2006, 2006.

Birch, M. E. and Cary, R. A.: Elemental carbon-based method for monitoring occupational exposures to particulate diesel exhaust, Aerosol Sci. Technol., 25, 221-241, 1996.

Bond, T. C. and Bergstrom, R. W.: Light absorption by carbonaceous particles: An investigative review, Aerosol Sci. Technol., 40, 27-67, doi:10.1080/02786820500421521, 2006.

Cachier, H., Bremond, M. P., and Buat-Menard, P.: Determination of atmospheric soot carbon with a simple thermal method, Tellus B, 41, 379-390, 1989.

Cadle, S. H., Groblicki, P. J., and Stroup, D. P.: Automated carbon analyzer for particulate samples, Anal. Chem., 52, 2201-2206, 1980.

Calzolai, G., Bernardoni, V., Chiari, M., Fedi, M. E., Lucarelli, F., Nava, S., Riccobono, F., Taccetti, F., Valli, G., and Vecchi, R.: The new sample preparation line for radiocarbon measurements on atmospheric aerosol at LABEC, Nucl. Instrum. Meth. B., 269, 203-208, 2011.

Castro, L. M., Pio, C. A., Harrison, R. M., and Smith, D. J. T.: Carbonaceous aerosol in urban and rural European atmospheres: estimation of secondary organic carbon concentrations, Atmos. Environ., 33, 2771-2781, 1999.

Cavalli, F., Viana, M., Yttri, K. E., Genberg, J., and Putaud, J.-P.: Toward a standardised thermal-optical protocol for measuring atmospheric organic and elemental carbon: the EUSAAR protocol, Atmos. Meas. Tech., 3, 79-89, doi:10.5194/amt-3-79-2010, 2010.

Chow, J. C., Watson, J. G., Crow, D., Lowenthal, D. H., and Merrifield, T.: Comparison of IMPROVE and NIOSH carbon measurements, Aerosol Sci. Technol., 34, 23-34, 2001.

Chow, J. C., Watson, J. G., Chen, L. W. A., Arnott, W. P., Moosmüller, H., and Fung, K.: Equivalence of elemental carbon by thermal/optical reflectance and transmittance with different temperature protocols, Environ. Sci. Technol., 38, 4414-4422, 2004.

Conny, J. M., Klinedinst, D. B., Wight, S. A., and Paulsen, J. L.: Optimizing thermal-optical methods for measuring atmospheric elemental (black) carbon: A response surface study, Aerosol Sci. Technol., 37, 703-723, 2003.

Currie, L. A.: Evolution and multidisciplinary frontiers of ${ }^{14} \mathrm{C}$ aerosol science, Radiocarbon, 42, 115-126, 2000.

Elmquist, M., Cornelissen, G., Kukulska, Z., and Gustafsson, Ö.: Distinct oxidative stabilities of char versus soot black carbon: Implications for quantification and environmental recalcitrance, Global Biogeochem. Cy., 20, GB2009, doi:10.1029/2005GB002629, 2006.

Fermo, P., Piazzalunga, A., Vecchi, R., Valli, G., and Ceriani, M.: A TGA/FT-IR study for measuring OC and EC in aerosol samples, Atmos. Chem. Phys., 6, 255-266, doi:10.5194/acp-6-255-2006, 2006.

Fung, K.: Particulate Carbon Speciation by $\mathrm{MnO}_{2}$ Oxidation, Aerosol Sci. Technol., 12, 122-127, 1990.

Gundel, L. A., Dod, R. L., Rosen, H., and Novakov, T.: The relationship between optical attenuation and black carbon concentration for ambient and source particles, Sci. Total Environ., 36, 197$202,1984$.

Gustafsson, Ö., Bucheli, T. D., Kukulska, Z., Andersson, M., Largeau, C., Rouzaud, J.-N., Reddy, C. M., and Eglinton, T. I.: Evaluation of a protocol for the quantification of black carbon in sediments, Global Biogeochem. Cy., 15, 881-890, 2001.

Highwood, E. J. and Kinnersley, R. P.: When smoke gets in our eyes: The multiple impacts of atmospheric black carbon on climate, air quality and health, Environ. Int., 32, 560-566, 2006.

Hodzic, A., Jimenez, J. L., Prévôt, A. S. H., Szidat, S., Fast, J. D., and Madronich, S.: Can 3-D models explain the observed fractions of fossil and non-fossil carbon in and near Mexico City?, Atmos. Chem. Phys., 10, 10997-11016, doi:10.5194/acp10-10997-2010, 2010.

Huang, L., Brook, J. R., Zhang, W., Li, S. M., Graham, L., Ernst, D., Chivulescu, A., and Lu, G.: Stable isotope measurements of carbon fractions (OC/EC) in airborne particulate: A new dimension for source characterization and apportionment, Atmos. Environ., 40, 2690-2705, 2006.

Iwatsuki, M., Kyotani, T., and Matsubara, K.: Fractional determination of elemental carbon and total soluble and insoluble organic compounds in airborne particulate matter by thermal analysis combined with extraction and heavy liquid separation, Anal. Sci., 14, 321-326, 1998.

Jimenez, J. L., Canagaratna, M. R., Donahue, N. M., Prevot, A. S. H., Zhang, Q., Kroll, J. H., DeCarlo, P. F., Allan, J. D., Coe, H., Ng, N. L., Aiken, A. C., Docherty, K. S., Ulbrich, I. M., Grieshop, A. P., Robinson, A. L., Duplissy, J., Smith, J. D., Wilson, K. R., Lanz, V. A., Hueglin, C., Sun, Y. L., Tian, J., 
Laaksonen, A., Raatikainen, T., Rautiainen, J., Vaattovaara, P., Ehn, M., Kulmala, M., Tomlinson, J. M., Collins, D. R., Cubison, M. J., Dunlea, E. J., Huffman, J. A., Onasch, T. B., Alfarra, M. R., Williams, P. I., Bower, K., Kondo, Y., Schneider, J., Drewnick, F., Borrmann, S., Weimer, S., Demerjian, K., Salcedo, D., Cottrell, L., Griffin, R., Takami, A., Miyoshi, T., Hatakeyama, S., Shimono, A., Sun, J. Y., Zhang, Y. M., Dzepina, K., Kimmel, J. R., Sueper, D., Jayne, J. T., Herndon, S. C., Trimborn, A. M., Williams, L. R., Wood, E. C., Middlebrook, A. M., Kolb, C. E., Baltensperger, U., and Worsnop, D. R.: Evolution of Organic Aerosols in the Atmosphere, Science, 326, 1525-1529, doi:10.1126/science.1180353, 2009.

Lanz, V. A., Prévôt, A. S. H., Alfarra, M. R., Weimer, S., Mohr, C., DeCarlo, P. F., Gianini, M. F. D., Hueglin, C., Schneider, J., Favez, O., D'Anna, B., George, C., and Baltensperger, U.: Characterization of aerosol chemical composition with aerosol mass spectrometry in Central Europe: an overview, Atmos. Chem. Phys., 10, 10453-10471, doi:10.5194/acp-10-10453-2010, 2010.

Lavanchy, V. M. H., Gäggeler, H. W., Schotterer, U., Schwikowski, M., and Baltensperger, U.: Historical record of carbonaceous particle concentrations from a European high-alpine glacier (Colle Gnifetti, Switzerland), J. Geophys. Res., D104, 21227-21236, 1999.

Levin, I., Naegler, T., Kromer, B., Diehl, M., Francey, R. J., GomezPelaez, A. J., Steele, L. P., Wagenbach, D., Weller, R., and Worthy, D. E.: Observations and modelling of the global distribution and long-term trend of atmospheric ${ }^{14} \mathrm{CO}_{2}$, Tellus B, 62, 26-46, 2010.

Mauderly, J. L. and Chow, J. C.: Health effects of organic aerosols, Inhal. Toxicol., 20, 257-288, 2008.

Mayol-Bracero, O. L., Guyon, P., Graham, B., Roberts, G., Andreae, M. O., Decesari, S., Facchini, M. C., Fuzzi, S., and Artaxo, P.: Water-soluble organic compounds in biomass burning aerosols over Amazonia - 2. Apportionment of the chemical composition and importance of the polyacidic fraction, J. Geophys. Res., 107, 8091, doi:10.1029/2001JD000522, 2002.

Minguillón, M. C., Perron, N., Querol, X., Szidat, S., Fahrni, S. M., Alastuey, A., Jimenez, J. L., Mohr, C., Ortega, A. M., Day, D. A., Lanz, V. A., Wacker, L., Reche, C., Cusack, M., Amato, F., Kiss, G., Hoffer, A., Decesari, S., Moretti, F., Hillamo, R., Teinilä, K., Seco, R., Peñuelas, J., Metzger, A., Schallhart, S., Müller, M., Hansel, A., Burkhart, J. F., Baltensperger, U., and Prévôt, A. S. H.: Fossil versus contemporary sources of fine elemental and organic carbonaceous particulate matter during the DAURE campaign in Northeast Spain, Atmos. Chem. Phys., 11, 12067-12084, doi:10.5194/acp-11-12067-2011, 2011.

Mohn, J., Szidat, S., Fellner, J., Rechberger, H., Quartier, R., Buchmann, B., and Emmenegger, L.: Determination of biogenic and fossil $\mathrm{CO}_{2}$ emitted by waste incineration based on ${ }^{14} \mathrm{CO}_{2}$ and mass balances, Bioresour. Technol., 99, 6471-6479, doi:10.1016/j.biortech.2007.11.042, 2008.

Novakov, T. and Corrigan, C. E.: Thermal characterization of biomass smoke particles, Mikrochim. Acta, 119, 157-166, 1995.

Perron, N., Sandradewi, J., Alfarra, M. R., Lienemann, P., Gehrig, R., Kasper-Giebl, A., Lanz, V. A., Szidat, S., Ruff, M., Fahrni, S., Wacker, L., Baltensperger, U., and Prévôt, A. S. H.: Composition and sources of particulate matter in an industrialised Alpine valley, Atmos. Chem. Phys. Discuss., 10, 9391-9430, doi:10.5194/acpd-10-9391-2010, 2010.
Phuah, C. H., Peterson, M. R., Richards, M. H., Turner, J. H., and Dillner, A. M.: A Temperature calibration procedure for the Sunset laboratory carbon aerosol analysis lab instrument, Aerosol Sci. Technol., 43, 1013-1021, 2009.

Piazzalunga, A., Bernardoni, V., Fermo, P., Valli, G., and Vecchi, R.: Technical Note: On the effect of water-soluble compounds removal on EC quantification by TOT analysis in urban aerosol samples, Atmos. Chem. Phys., 11, 10193-10203, doi:10.5194/acp-11-10193-2011, 2011.

Pöschl, U.: Atmospheric aerosols: composition, transformation, climate and health effects, Angew. Chem. Int. Ed. Engl., 44, 7520 7540, 2005.

Ruff, M., Wacker, L., Gäggeler, H. W., Suter, M., Synal, H. A., and Szidat, S.: A gas ion source for radiocarbon measurements at 200 kV, Radiocarbon, 49, 307-314, 2007.

Ruff, M., Szidat, S., Gäggeler, H. W., Suter, M., Synal, H.A., and Wacker, L.: Gaseous radiocarbon measurements of small samples, Nucl. Instr. Meth. Phys. Res. B, 268, 790-794, doi:10.1016/j.nimb.2009.10.032, 2010.

Schmid, H., Laskus, L., Abraham, H. J., Baltensperger, U., Lavanchy, V., Bizjak, M., Burba, P., Cachier, H., Crow, D., Chow, J., Gnauk, T., Even, A., ten Brink, H. M., Giesen, K. P., Hitzenberger, R., Hueglin, C., Maenhaut, W., Pio, C., Carvalho, A., Putaud, J. P., Toom-Sauntry, D., and Puxbaum, H.: Results of the "carbon conference" international aerosol carbon round robin test stage I, Atmos. Environ., 35, 2111-2121, 2001.

Sandradewi, J., Prévôt, A. S. H., Szidat, S., Perron, N., Alfarra, M. R., Lanz, V. A., Weingartner, E., and Baltensperger, U.: Using Aerosol Light Absorption Measurements for the Quantitative Determination of Wood Burning and Traffic Emission Contributions to Particulate Matter, Environ. Sci. Technol., 42, 33163323, doi:10.1021/es702253m, 2008a.

Sandradewi, J., Prévôt, A. S. H., Alfarra, M. R., Szidat, S., Wehrli, M. N., Ruff, M., Weimer, S., Lanz, V. A., Weingartner, E., Perron, N., Caseiro, A., Kasper-Giebl, A., Puxbaum, H., Wacker, L., and Baltensperger, U.: Comparison of several wood smoke markers and source apportionment methods for wood burning particulate mass, Atmos. Chem. Phys. Discuss., 8, 8091-8118, doi:10.5194/acpd-8-8091-2008, 2008b.

Stuiver, M. and Polach, H. A.: Discussion: Reporting of ${ }^{14} \mathrm{C}$ data, Radiocarbon, 19, 355-363, 1977.

Subramanian, R., Khlystov, A. Y., and Robinson, A. L.: Effect of peak inert-mode temperature on elemental carbon measured using thermal-optical analysis, Aerosol Sci. Technol., 40, 763-780, 2006.

Synal, H. A., Stocker, M., and Suter, M.: MICADAS: A new compact radiocarbon AMS system, Nucl. Instr. Meth. Phys. Res. B. 259, 7-13, 2007.

Szidat, S.: Sources of Asian haze, Science, 323, 470-471, doi:10.1126/science.1169407, 2009.

Szidat, S., Jenk, T. M., Gäggeler, H. W., Synal, H. A., Hajdas, I., Bonani, G., and Saurer, M.: THEODORE, a two-step heating system for the EC/OC determination of radiocarbon $\left({ }^{14} \mathrm{C}\right)$ in the environment, Nucl. Instr. Meth. Phys. Res. B, 223-224, 829-836, doi:10.1016/j.nimb.2004.04.153, 2004a.

Szidat, S., Jenk, T. M., Gäggeler, H. W., Synal, H. A., Fisseha, R., Baltensperger, U., Kalberer, M., Samburova, V., Wacker, L., Saurer, M., Schwikowski, M., and Hajdas, I.: Source apportionment of aerosols by ${ }^{14} \mathrm{C}$ measurements in different carbonaceous 
particle fractions, Radiocarbon, 46, 475-484, 2004b.

Szidat, S., Jenk, T. M., Synal, H.-A., Kalberer, M., Wacker, L., Hajdas, I., Kasper-Giebl, A., and Baltensperger, U.: Contributions of fossil fuel, biomass-burning, and biogenic emissions to carbonaceous aerosols in Zurich as traced by ${ }^{14} \mathrm{C}$, J. Geophys. Res., 111, D07206, doi:10.1029/2005jd006590, 2006.

Szidat, S., Prevot, A. S. H., Sandradewi, J., Alfarra, M. R., Synal, H. A., Wacker, L., and Baltensperger, U.: Dominant impact of residential wood burning on particulate matter in Alpine valleys during winter, Geophys. Res. Lett., 34, L05820, doi:10.1029/2006g1028325, 2007.

Szidat, S., Ruff, M., Perron, N., Wacker, L., Synal, H.-A., Hallquist, M., Shannigrahi, A. S., Yttri, K. E., Dye, C., and Simpson, D.: Fossil and non-fossil sources of organic carbon (OC) and elemental carbon (EC) in Göteborg, Sweden, Atmos. Chem. Phys., 9, 1521-1535, doi:10.5194/acp-9-1521-2009, 2009.

Turpin, B. J., Saxena, P., and Andrews, E.: Measuring and simulating particulate organics in the atmosphere: problems and prospects, Atmos. Environ., 34, 2983-3013, 2000.

Wacker, L., Fahrni, S. M., Hajdas, I., Molnar, M., Synal, H. A., Szidat, S., and Zhang, Y. L.: A versatile gas interface for routine radiocarbon analysis with a gas ion source, Nucl. Instr. Meth. Phys. Res. B., doi:10.1016/j.nimb.2012.02.009, in press, 2012.

Wang, Y., Chung, A., and Paulson, S. E.: The effect of metal salts on quantification of elemental and organic carbon in diesel exhaust particles using thermal-optical evolved gas analysis, Atmos. Chem. Phys., 10, 11447-11457, doi:10.5194/acp-1011447-2010, 2010.
Weber, R. J., Sullivan, A. P., Peltier, R. E., Russell, A., Yan, B., Zheng, M., de Gouw, J., Warneke, C., Brock, C., Holloway, J. S., Atlas, E. L., and Edgerton, E.: A study of secondary organic aerosol formation in the anthropogenicinfluenced southeastern United States, J. Geophys. Res., 112, D13302, doi:10.1029/2007JD008408, 2007.

Yang, H. and Yu, J. Z.: Uncertainties in charring correction in the analysis of elemental and organic carbon in atmospheric particles by thermal/optical methods, Environ. Sci. Technol., 36, 51995204, 2002.

Yu, J. Z., Xu, J., and Yang, H.: Charring characteristics of atmospheric organic particulate matter in thermal analysis, Environ. Sci. Technol., 36, 754-761, 2002.

Zencak, Z., Elmquist, M., and Gustafsson, Ö.: Quantification and radiocarbon source apportionment of black carbon in atmospheric aerosols using the CTO-375 method, Atmos. Environ., 41, 7895-7906, 2007.

Zhang, Y. L., Liu, D., Shen, C. D., Ding, P., and Zhang, G.: Development of a preparation system for the radiocarbon analysis of organic carbon in carbonaceous aerosols in China, Nucl. Instr. Meth. Phys. Res. B, 268, 2831-2834, doi:10.1016/j.nimb.2010.06.032, 2010. 